A "Cool Kids" Cognitive-Behavioral Therapy Group for Youth with Anxiety Disorders:

Part 1, The Case of Erik

I. Lundkvist-Houndoumadi \& M. Thastum

Pragmatic Case Studies in Psychotherapy, http://pcsp.libraries.rutgers.edu

Volume 9, Module 2, Article 2, pp. 122-178, 06-26-13 [copyright by authors]

EDITOR'S NOTE: This is the first of two articles documenting a cognitive-behavioral therapy group for six children, aged 8-12, with a variety of anxiety disorders. This article, Part 1, presents an in-depth investigation of the process and outcome in the group of one of the clients, Erik, who responded most positively to the therapy. The second article, Part 2, reviews the process and outcome of all six children, with a focus on the process and outcome differences between responders and nonresponders. It should also be noted that this article is based on an earlier, unpublished version of this paper that provides more technical details about the study and is available from the authors (Lundkvist-Houndoumadi \& Thastum, 2010).

\title{
A "Cool Kids" Cognitive-Behavioral Therapy Group for Youth with Anxiety Disorders: Part 1, The Case of Erik
}

\section{IRENE LUNDKVIST-HOUNDOUMADI ${ }^{\text {a,b }}$ \& MIKAEL THASTUM $^{\text {a }}$}

${ }^{\mathrm{a}}$ The Anxiety Disorder Clinic for Children and Adolescents, Dept. of Psychology, Aarhus University, Denmark b

${ }^{\mathrm{b}}$ Correspondence regarding this article should be addressed to Irene Lundkvist-Houndoumadi, Department of Psychology and Behavioural Sciences, Aarhus University, Bartholins Allé 9, 8000 Aarhus C., Denmark. Email: irenelh@psy.au.dk

\begin{abstract}
This case study involves a 12-year-old boy, Erik, with cognitive difficulties, who also suffered from multiple anxiety disorders (specifically, he met the diagnostic criteria of Generalized Anxiety, Specific Phobias, Social Phobia, and Separation Anxiety). Erik and his family were treated for 10 sessions over three months with the "Cool Kids " cognitive-behavioral therapy (CBT) program developed by Ronald Rapee and his colleagues (Rapee et al., 2006). The treatment took place in a university training clinic in Aarhus, Denmark. CBT was conducted in a group format, with both children and their families taking an active part, and included cognitive restructuring, gradual exposure, child management training, and skills training in areas such as assertiveness. Results show that therapy effectively reduced the child's anxiety symptoms, as measured by the Anxiety Disorder Interview Schedule for Children and Parents (ADIS-IV P/C) and by the Spence Children's Anxiety Scale (SCAS). Additional quantitative and qualitative data indicate an overall positive therapeutic outcome, which was maintained at 3 months and 15 months after the conclusion of treatment. A primary aim of the case study was to investigate the mechanisms of change leading to success in Erik's case, focusing on the role of parental inclusion in the therapy and the necessary accommodations made to the child's cognitive developmental level. For example, through parents' engagement in therapy, it was possible to alter their expectations and behaviors, with Erik's mother learning how to be less overprotective and control her own anxiety, functioning as a positive role model for her child. Furthermore, the present study stresses the significance of accommodating the treatment to the child's cognitive developmental level, such that Erik's cognitions were initially challenged successfully through gradual exposures and only later addressed with cognitive restructuring, aided by the treatment given to his parents and Erik's advancing cognitive maturation.
\end{abstract}

Key words: childhood anxiety disorders; Cognitive Behavioral Therapy (CBT); Cool Kids Program; cognitive restructuring; parental anxiety; case study; clinical case study 
A "Cool Kids" Cognitive-Behavioral Therapy Group for Youth with Anxiety Disorders:

Part 1, The Case of Erik

I. Lundkvist-Houndoumadi \& M. Thastum

Pragmatic Case Studies in Psychotherapy, http://pcsp.libraries.rutgers.edu

Volume 9, Module 2, Article 2, pp. 122-178, 06-26-13 [copyright by authors]

\section{CASE CONTEXT AND METHOD}

\section{A. The Clinical Setting}

The present study was carried out at the Anxiety Disorder Clinic for Children and Adolescents ("Children's Anxiety Clinic") run by the Department of Psychology of Aarhus University in Denmark, as part of a clinical training program. While the Department had been running an Anxiety Specialty Clinic for Adults for a few years previously, this case took place in the first year that the Children's Clinic functioned. The Children's Anxiety Clinic offers cognitive-behavioral treatment (CBT) to children with anxiety disorders, provided free-of-charge by masters-level, clinical psychology student therapists supervised by senior faculty.

Each of the eight student therapists who participated in the two-semester-long training program were in at least the eighth semester of study in the clinical psychology program; the clients that they saw in the Children's Anxiety Clinic were usually their first psychotherapy clients. The first semester of the clinical training program included a theoretical course on CBT, depression, and anxiety disorders. There was also a practical component in both semesters, in which two cycles of group therapy (based on the Cool Kids Program (Rapee et al., 2006; see description below) were implemented, each cycle consisting of 10 sessions. In the first cycle of group therapy, which took place in the spring of 2009, student therapists were assigned to the six children with anxiety disorders who had been recruited. In addition, student therapists were offered the option of seeing clients in individual therapy. This study will focus on one of the clients (Erik), who was one of the six children in the first cycle of the group therapy sessions. We have also written up an analysis of the process and outcome of all six children in Erik's group, which accompanies the present article in this issue of the PCSP journal (LundkvistHoundoumadi \& Thastum, 2013).

\section{B. The Rationale for Selecting the Client}

Erik's family contacted the clinic after hearing about the program from a school psychologist. He was selected for the program because his anxiety problems seemed severe, as he fulfilled the criteria for multiple diagnoses on the Anxiety Disorder Interview Schedule for Child/Parent (ADIS-IV C/P; Albano \& Silverman, 1996 (see Table 1). The program seemed appropriate for Erik, as it is suited for children with any principal diagnosis of an anxiety disorder. Although he was somewhat older (12 years) than the other children involved in the treatment, who were between 8 and 10 years of age, the clinicians decided to include him in the group after a discussion with the parents and Erik on the issue of his age. His parents stated that he liked playing with younger children, and Erik's teacher had stated that he was one year behind in school. Additionally, the father believed that participating in a group with younger children might give Erik a feeling of mastery and being "ahead" of the others, thereby bolstering his selfesteem.

Erik had a positive outcome in the therapy. A primary aim of this case study was to investigate the mechanisms of change leading to success, focusing on the role of parental inclusion in therapy and necessary accommodations made for the child's cognitive developmental level. 
A "Cool Kids" Cognitive-Behavioral Therapy Group for Youth with Anxiety Disorders:

Part 1, The Case of Erik

I. Lundkvist-Houndoumadi \& M. Thastum

Pragmatic Case Studies in Psychotherapy, http://pcsp.libraries.rutgers.edu

Volume 9, Module 2, Article 2, pp. 122-178, 06-26-13 [copyright by authors]

\section{Confidentiality}

The client's name and some of the biographical information have been changed in order to protect his and his family's identity. These changes were made while bearing in mind the importance of preserving information that is of clinical importance.

\section{Method}

$\underline{\text { Procedures for Recruitment and Assessment Measures }}$

The families of children involved in the treatment program were self-referred, and learned about the clinic from a variety of sources, including advertisements in the local newspaper and the Internet, as well as information from school psychologists. The clients and family members who contacted the Children's Clinic were asked to send in a brief description of the problem(s), which was used for diagnostic screening in order to restrict intake to children suffering from anxiety disorders. The exclusion criteria eliminated children with non-treated ADHD, autism spectrum disorders, selective mutism, severe conduct disorders, and mental deficiency from the group treatment for anxiety.

Following the initial screening, the child and parents were invited to a structured clinical interview based on the ADIS-IV C/P. A second meeting was then arranged with the parents, in which an interview was carried out in order to obtain more background information concerning the child's developmental history, the composition of the family, and possible protective or maintaining factors with regard to the child's anxiety problems. In cases in which children were diagnosed with an anxiety disorder and had the appropriate age, they were offered group treatment. Otherwise, they were offered individual treatment or referred to another treatment facility.

At pre-treatment, the parents completed an intake questionnaire assessing the family's socioeconomic status and the child's presenting problems, including when the problems first appeared, professionals who had been involved in the treatment of the problems, and whether medication was being administered. In addition the ADIS-C/P was administered, and the parents and child completed four standardized, self-report questionnaires, which are described in Table 1. These measures included: the Strengths and Difficulties Questionnaire (SDQ; Goodman, \& Scott, 1999); the Beck Youth Inventories of Emotional and Social Impairment (BYI; Beck, Beck \& Jolly, 2001); the Spence Children’s Anxiety Scale (SCAS; Spence, 1998); and the Children’s Anxiety Life Inference Scale (CALIS; Lyneham et al., in preparation).

At post-treatment, the four self-report measures were repeated and a treatment satisfaction measure was collected.

At the first follow-up (3 months after treatment), the four self-report measures were repeated and the ADIS-P was readministered.

At the second follow-up (15 months after treatment), the four self-report measures and the ADIS-P were again repeated, and rating scales specially constructed by the first 
A "Cool Kids" Cognitive-Behavioral Therapy Group for Youth with Anxiety Disorders:

Part 1, The Case of Erik

I. Lundkvist-Houndoumadi \& M. Thastum

Pragmatic Case Studies in Psychotherapy, http://pcsp.libraries.rutgers.edu

Volume 9, Module 2, Article 2, pp. 122-178, 06-26-13 [copyright by authors]

author were administered. (These are described in Table 1)

Also at 15 month follow-up, a Clinical Global Impression-Improvement of Anxiety Scale (CGI-I) was administered, based on all the quantitative and qualitative information gained at this assessment. This is a single rating (1-7) of the child's condition in comparison to his/her condition prior to the initiation of treatment based on behaviors, symptoms, and functioning in all aspects of the child's life as reflected in both the quantitative and qualitative reports of both the parents and the child. (This measure is described in Table 2.)

\section{$\underline{\text { Treatment Program and Outcome Evaluation Procedures }}$}

The Cool Kids Child and Adolescent Anxiety Program Therapist Manual (Rapee, Lyneham, Schniering, Wuthrich, Abbott, Hudson \& Wignall, 2006) was used as a guideline in therapy. Additionally, a Cool Kids Program-Child Workbook and a Cool Kids Program-Parent's Workbook (Lyneham, Abbott, Wignall, \& Rapee, 2003) were handed out in the first session and used throughout therapy.

Outcome was quantitatively measured by changes on the four self-standardized selfreport measures. A Reliable Change Index (RCI; Jacobson \& Truax, 1991) was calculated in order to measure the reliability of the change following treatment. The calculation of effect sizes was based on Cohen's d statistic (Cohen, 1988). The differences obtained in measures before treatment, after treatment, at a 3-month follow-up, and at 15-month follow-up were compared to the standard deviation of a clinical group.

\section{THE CLIENT}

When Erik came for therapy he was 12 years old and in the 5th grade. He had a Danish ethnic background, came from a working class family, and lived in a neighborhood where most families had a cultural background different from his. He lived with his parents, Mia and Ib, who were about 40 years old, and his younger brother, aged 9. Erik's problems became apparent when he changed school in the beginning of second grade. Erik was diagnosed (American Psychiatric Association, 2000) with Obsessive Compulsive Disorder (OCD) and Generalized Anxiety Disorder (GAD) by a child psychiatrist he had stopped seeing shortly before the beginning of his treatment at the clinic; the family ended treatment with this psychiatrist because the planned number of sessions had been completed. The parents thought that Erik needed more help and did not feel they could handle their child's anxiety problems alone. They turned to the school psychologist for help, who informed them about our program. Parents then sent an e-mail (see Table 3) describing how Erik's main difficulties with anxiety were problematic across many areas of his life, characterizing it a significant handicap in their everyday lives. A detailed description of Erik at intake can be found in the assessment section. 
A "Cool Kids" Cognitive-Behavioral Therapy Group for Youth with Anxiety Disorders:

Part 1, The Case of Erik

I. Lundkvist-Houndoumadi \& M. Thastum

Pragmatic Case Studies in Psychotherapy, http://pcsp.libraries.rutgers.edu

Volume 9, Module 2, Article 2, pp. 122-178, 06-26-13 [copyright by authors]

\section{GUIDING CONCEPTION WITH RESEARCH}

\section{Childhood Anxiety Disorders}

Anxiety is assumed to be a tripartite construct involving physiological, cognitive, and behavioral components. Physiological arousal occurs in the form of autonomic nervous system activity, which prepares the individual for "fight or flight." The cognitive component involves a narrowing of attention or a shift in focus toward the threat cues in the situation. This is accompanied by certain thoughts and images that are followed by behaviors, which are a response to the perception of the situation as dangerous (see Barlow, 2002). A distinction between normal adaptive fear and maladaptive fear, according to Ollendick, King and Yule (1994), is that adaptive fear is based on a realistic appraisal of the potential threat. In contrast, maladaptive fear is based on an unrealistic appraisal of the threat that the specific stimulus poses to the individual.

It is normal and expected for children to have certain fear and anxiety reactions during development, with the focus of anxiety changing at different ages and cognitive developmental levels (Albano et al., 2001). Children are expected to grow out of certain fears as they mature cognitively (e.g., no longer believing that there are monsters under the bed); otherwise anxiety becomes problematic, as it results in significant distress and impairment (Albano et al., 1996; Kazdin \& Weisz, 1998; Kendall, 2000). From a clinical psychological perspective, children are frequently referred for anxiety treatment when the fear interferes with the activities that would be expected at their specific developmental level (Carr, 1999).

An understanding of the factors involved in the etiology and maintenance of childhood anxiety can be described through the model of Rapee (2001). Genetic and environmental factors that have been related to child anxiety through multiple studies have been integrated in this model, describing many possible pathways to the development of an anxiety disorder. As illustrated in Figure 1, genetic factors determine that some children are born with anxious vulnerability, which may be manifested through the child's temperament and evidenced by high levels of arousal and emotionality, as well as avoidance and cognitive processing bias. This vulnerability to anxiety may elicit in others, such as parents, behaviors that maintain or exacerbate anxiety. Parental anxiety, which is also likely responsible for the genetic factors that the child inherited in the first place, may also influence parents' behavior, which becomes overprotective, thus providing environmental support of avoidance of feared situations by the child, whose temperament serves to maintain that overprotection. Parental anxiety also interferes with the parents' ability to cope in difficult situations, thereby exacerbating the possible adverse effects of the social environment that is reciprocally influenced by the child's vulnerability to anxiety. Rapee's model draws attention to the external environmental effects that, when combined with the child's anxious vulnerability, leads to the development of an anxiety disorder.

The bi-directionality of influences between the child's temperament and the environment is supported by studies indicating that biological parents of children with anxiety are often overcontrolling and negative towards them (see Bögels \& Brechman-Toussaint, 2006), and biologically unrelated mothers also tend to be over-involved when interacting with anxious 
A "Cool Kids" Cognitive-Behavioral Therapy Group for Youth with Anxiety Disorders:

Part 1, The Case of Erik

I. Lundkvist-Houndoumadi \& M. Thastum

Pragmatic Case Studies in Psychotherapy, http://pcsp.libraries.rutgers.edu

Volume 9, Module 2, Article 2, pp. 122-178, 06-26-13 [copyright by authors]

children (Hudson, Doyle \& Gar, 2009). Through observational learning and by obtaining primarily threat-related negative information (Muris, Steerneman, Merckelbach, \& Meester, 1996), the children may unwittingly enhance the perception of the threat and simultaneously diminish a sense of personal control over the threat. This may lead the children to believe that they cannot handle "dangerous" situations and avoid them. This in turn maintains and/or enhances children's anxiety problems, as they do not learn that the feared situation is not dangerous and one that they can master (Allen \& Rapee, 2005).

\section{CBT with Children with Anxiety Disorders}

Anxiety disorders are among the most prevalent childhood psychiatric disorders (Essau, Conradt, \& Petermann, 2000). Studies show that many children who experience anxiety continue to have problems in adulthood (Pine et al., 1998). Thus, the need for effective treatment is great. A recent meta-analysis provided strong evidence that psychological treatment of anxiety disorders in children and young people is associated with symptomatic change, which is significantly greater compared to an active psychological control condition (Reynolds, Wilson, Austin \& Hooper, 2012).

\section{The Role of Cognitions in CBT with Children with Anxiety}

The development of theoretically determined testable models is a strength of CBT, as it provides a rationale for intervention. It is claimed that affect and behavior are largely determined by cognitions, and that the focus for intervention should be challenging cognitive distortions (Fennel, 1989). In the case of CBT with children, additional developmental issues are important. There appears to be general agreement that older children may be more responsive to cognitive approaches, whereas younger children may be more responsive to behaviorally oriented treatment techniques (O’Connor \& Creswell, 2005). In order to assess the need for cognitive interventions in children with anxiety, it is important to find out whether deficient or abnormal cognitive processing is associated with anxiety problems in childhood in the first place (Bolton, 2005).

Studies show that children, similar to adults, use cognitive appraisals associated with anxiety (Chorpita et al., 1996). According to Kendall's (1985) cognitive theory, the pathological manifestations of anxiety can be described as a result of the over-activity of schemas, which are organized around themes of vulnerability and danger. There is evidence that children with anxiety disorders tend to misperceive ambiguous situations as threatening and are overly selffocused, reporting increased negative expectations (Kendall et al., 1992; Kendall \& PanichelliMindel, 1995). Although findings indicate that anxious children display biases and distortions at different stages of the processing of anxiety related information (Muris \& Field, 2008), there is a need to assess the specific kind and content of the cognitive distortions implicated in the generation and/or maintenance of the anxiety disorder of the individual child (Bolton, 2005).

Even when cognitive distortions are present, the theoretical models used with adults are not enough to describe a child's problems. The role of the family and wider systemic factors that impact the child and influence the generation and/or maintenance of the anxiety disorder should be also considered (Stallard, 2002) and addressed in the interventions chosen. 
A "Cool Kids" Cognitive-Behavioral Therapy Group for Youth with Anxiety Disorders:

Part 1, The Case of Erik

I. Lundkvist-Houndoumadi \& M. Thastum

Pragmatic Case Studies in Psychotherapy, http://pcsp.libraries.rutgers.edu

Volume 9, Module 2, Article 2, pp. 122-178, 06-26-13 [copyright by authors]

\section{The Inclusion of the Family in CBT}

Given the potential role that parents play in the maintenance of anxiety disorders in children (e.g., Gar, Hudson, \& Rapee, 2005; Wood, McLeod, Sigman, Chu, \& Hwang, 2003; Hudson \& Rapee, 2009; Bögels \& Brechman-Toussaint, 2006), it makes sense to include parents as a central part of the treatment. Although the evidence from studies comparing child-focused treatment to family-focused treatment does not lead to clear conclusions regarding their relative effectiveness (Barrett et al., 1996; Barrett, 1998; Cobham et al., 1998; Mendlowitz et al., 1999; Shortt et al., 2001; Silverman et al., 1999; Spence et al., 2000), findings from those treatment studies suggest that family-based CBT is either as effective or more effective than individual CBT (Ginsburg \& Schlossberg, 2002). Parent inclusion is particularly effective in the case of younger children (7-10 year-olds) and girls (Barrett, Dadds, \& Rapee, 1996; Mendlowitz et al., 1999). This may be the case because most family-based treatments for child anxiety teach parents to model coping behaviors and successful problem solving (Ginsburg \& Schlossberg, 2002); however, while younger children regularly view their parents as models, adolescents are usually more influenced by their peers.

Parental anxiety has been found to interfere with the development of the parents' adaptive coping skills and leads to behaviors that may exacerbate the anxiety of their children, thereby adding an additional risk factor in the maintenance of childhood anxiety (Ginsburg \& Schlossberg, 2002). There is actually some evidence indicating that a family-based treatment may be more effective for children whose parents also have an anxiety disorder (Cobham, Dads, \& Spence, 1998).

Fathers are often included less than mothers in the treatment of developmental psychopathology (Lazar, Sagi, \& Fraser, 1991), and childhood anxiety disorders are no exception. Research on normal development indicates that fathers play an important and different role than mothers in the protection of children against severe anxiety (Bögels \& Phares, 2008), and studies of various types of developmental psychopathology reveal better long-term effects when fathers are included in treatment (e.g. Bagner \& Eyberg, 2003). Although little is known about fathers' specific role in child anxiety treatment, these findings may indicate that their role should not be overlooked.

\section{The Cool Kids Program}

The Anxiety Disorder Clinic for Children and Adolescents offers cognitive behavioral treatment (CBT) based on the Cool Kids Program that was developed in the Macquarie University Anxiety Research Unit (Rapee, Wignall, Hudson \& Schniering, 2000). The Cool Kids Program has been extensively evaluated in controlled trials and results demonstrate that up to $80 \%$ of children who complete the program are diagnosis-free or markedly improved. These results have been shown to persist for up to 6 years (Rapee et al., 2006).

The Cool Kids Program is a CBT program for children, aged 6-12 years old, who meet the criteria for a principal diagnosis of any anxiety disorder. The program aims to teach children cognitive behavioral skills that are designed to combat anxiety. First, the program helps children recognize emotions such as fear, stress, and anxiety, as well as related thoughts. Furthermore, it 
A "Cool Kids" Cognitive-Behavioral Therapy Group for Youth with Anxiety Disorders:

Part 1, The Case of Erik

I. Lundkvist-Houndoumadi \& M. Thastum

Pragmatic Case Studies in Psychotherapy, http://pcsp.libraries.rutgers.edu

Volume 9, Module 2, Article 2, pp. 122-178, 06-26-13 [copyright by authors]

helps children to challenge beliefs associated with feeling anxious and generate alternative, more realistic thoughts via cognitive restructuring (detective thinking). Lastly, it encourages children to gradually engage with feared activities in more positive ways. Exposure to anxiety provoking situations is gradually achieved through the joint creation of stepladders with the child and parents. Furthermore, children are offered social skills training, problem solving, and worry surfing, which aims at building tolerance to the anxious feelings and helping children to refocus attention on everyday activities so as to prevent worries from interfering in the day-to-day functioning. Finally, there is an additional component for parents that informs them of the treatment principles and teaches them alternate ways of interacting with their child.

The role of the therapist is to coach and teach children and their parents about issues related to anxiety and coping skills through role playing, therapist modeling, working through hypothetical examples provided in the workbook, games, in vivo exposure, and interactive discussions. The importance of the work that the family does between sessions is also stressed. Upon agreement with the authors of the original program, Mikael Thastum, who has worked with the program in Sydney, introduced it in Denmark. Table 4 presents a detailed summary of the session-by-session content of the Cool Kids Program in the Aarhus Children's Anxiety Clinic.

\section{ASSESSMENT OF THE CLIENT'S PROBLEMS, GOALS, STRENGTHS, AND HISTORY}

Erik's anxiety problems were first described in the e-mail (see Table 3) that his parents sent to the Anxiety Clinic. A more detailed picture emerged from the two assessment interviews and the questionnaires completed (see Table 5 for pre-treatment scores).

\section{Demographic Information and Erik's Extended Family}

Erik lived with both his parents, who were working full time when the therapy started. Mia (his mother) suffered from anxiety and had seen a psychologist in the past, although she reported that the treatment did not help her. Mia's main problem was that she became very afraid when she was alone in new places. She believed that this was due to her being admitted to a home for infants for three months when she was a few months old and her mother was hospitalized while her father was working full time and could not take care of her. Furthermore, she suffered from claustrophobia. Mia also commented that she was afraid that she was partly responsible for Erik's anxiety, because of her genetic contribution and overprotective behavior. Erik's brother suffered from encopresis and had daily problems with his defecation. In the more extended family, the mother's sister had issues with panic attacks and feared leaving her house, and her husband had Major Depressive Disorder. Erik's cousin was initially diagnosed with Obsessive-Compulsive Disorder, but this was later changed to Generalized Anxiety Disorder; she received medication and psychotherapy and was doing better, although she was still afraid of being home alone. 
A "Cool Kids" Cognitive-Behavioral Therapy Group for Youth with Anxiety Disorders:

Part 1, The Case of Erik

I. Lundkvist-Houndoumadi \& M. Thastum

Pragmatic Case Studies in Psychotherapy, http://pcsp.libraries.rutgers.edu

Volume 9, Module 2, Article 2, pp. 122-178, 06-26-13 [copyright by authors]

\section{Erik's View of His Presenting Problems}

While it was difficult for me ${ }^{1}$ as the clinician to establish eye contact with Erik in the first meeting, he seemed more relaxed and talkative in the second assessment meeting. The ADIS-C interview elicited information regarding Erik's specific phobias regarding doctors, dentists, and vaccinations. Otherwise, Erik did not seem to believe that he had any significant anxiety problems, providing rational explanations for why he was afraid of other things. As shown in his self-report scores in Table 5, the CALIS confirmed that Erik did not think anxiety interfered with his life; and the BYI did not show an elevated anxiety score.

A different picture emerged from the SCAS self-report. Erik’s total anxiety, GAD, and social anxiety scores were above the clinical cut-off point in the pre-treatment assessment. Similarly, in the SDQ, Erik scored within the clinical range on emotional symptoms. On the basis of these findings, it seemed that Erik often worried, but was reluctant to say so. It should be noted that the elevated score on the social phobia scale can be partly explained by the fact that Erik was not managing well in school and therefore might have had more reasons to fear social situations in school, where his academic knowledge was judged.

\section{Learning Difficulties}

While in therapy, Erik was being tested in school in order to determine whether his academic difficulties were due to anxiety or learning problems. According to Erik's teachers, he was about one year behind in academics. Ultimately, the school psychologist's report revealed that, according to the WISC-III intelligence test, Erik's processing speed, attention span, and auditory short-term memory fell below the expectations for his age group.

\section{The Parents' View of Erik's Problems}

Erik’s parents (particularly his mother) described Erik’s anxiety problems as being a big handicap for Erik and the family in everyday life. He was described as a boy who was afraid of many things, including being alone. As a result of this fear, he could not stay home alone or transport himself to places.

Erik worried about many things, including: doing the right thing, his health, his family's health, world problems he had heard about (such as war and terrorism), his parents' well-being, and being kidnapped. Erik's parents claimed to have tried reasoning with him; although he generally trusted their opinion, Erik still believed that he might be kidnapped. Erik was generally very afraid of (and therefore avoided) situations in which he might get hurt. As a result of his fears, he did not go to the dentist or learned how to swim or ride a bike.

Erik did not have many friends. According to Mia, other children did not understand him, as Erik's anxieties held him back from doing things that kids of his age do. Erik was concerned about what others thought of him. Although he was of normal weight, he avoided eating sweets

\footnotetext{
${ }^{1}$ refers to the first author (ILH), who was one of the two student therapists assigned to Erik.
} 
A "Cool Kids" Cognitive-Behavioral Therapy Group for Youth with Anxiety Disorders:

Part 1, The Case of Erik

I. Lundkvist-Houndoumadi \& M. Thastum

Pragmatic Case Studies in Psychotherapy, http://pcsp.libraries.rutgers.edu

Volume 9, Module 2, Article 2, pp. 122-178, 06-26-13 [copyright by authors]

in front of others and did not like to be seen in a bathing suit, as he was concerned about his body appearance.

On the basis of the parents' self-report questionnaires (see Table 5), it seemed that Erik's parents mostly shared a similar view of his anxiety problems. In the SCAS questionnaire both parents' total score and the scores for Generalized Anxiety Disorder and Social Phobia were in the clinical range, as were their scores for Obsessive-Compulsive Disorder according to his father, Ib. On the SDQ emotional problems were in the clinical range for both parents. Finally, the CALIS indicated that Mia (in contrast to Ib) believed that the anxiety problems interfered greatly with Erik's and her personal life; therefore her replies were in the clinical range.

\section{Family History}

Erik's parents described him as a child who had always had a fearful temperament. Erik had been developmentally behind and was examined by his doctor when he was 21 months old because of motor difficulties. While no physical problems were identified, he first learned to walk when he was 1.5 years old.

Erik's anxiety problems became obvious and the family was referred to a child psychiatrist for the first time in August 2007. Erik had just changed schools in the second grade and his parents had been shortly separated (the father had moved out for three weeks). It seems that this time was a very traumatic experience for Erik, as every time his parents argued, he exclaimed, "You promised you will stay together!"

\section{Diagnoses}

Based on the pre-treatment diagnostic interviews, the following diagnoses were given:

- ADIS-C (child version): Specific Phobia of Blood-Injection-Injury Type (fears of getting vaccinated, having a blood sample taken, doctors, and dentists). Clinical Severity Rating (CSR): 4.

- ADIS-P (parent version):

o Generalized Anxiety Disorder, CSR: 8;

o Specific Phobia of Blood-Injection-Injury Type, CSR: 8;

o Social Phobia, CSR: 7;

o Separation Anxiety Disorder, CSR: 6-7;

o Specific Phobia of Animal Type (bees), CSR: 6.

The final diagnoses that were given were identical to those of ADIS-P. The diagnoses given to Erik at different points in time are presented in Table 6. 
A "Cool Kids" Cognitive-Behavioral Therapy Group for Youth with Anxiety Disorders:

Part 1, The Case of Erik

I. Lundkvist-Houndoumadi \& M. Thastum

Pragmatic Case Studies in Psychotherapy, http://pcsp.libraries.rutgers.edu

Volume 9, Module 2, Article 2, pp. 122-178, 06-26-13 [copyright by authors]

\section{Strengths}

Erik was a very sweet and considerate boy. Although he was quiet at first, he quickly opened up and was cooperative in answering the questions at the interview. In response to a question posed to the parents regarding what strengths they believed they had as a family, Mia described how they spent a lot of time together as a family. They had a good relationship with one another and watched out for each other. Erik spent a lot of time with Mia's parents and had a good relationship with the extended family. Mia believed that the fact that her sister has a daughter with anxiety problems contributed to her understanding of Erik's anxiety, since she and her sister could talk about their difficulties. Mia added that this was very important, because it could be hard for people who did not have issues with anxiety to understand how anxiety can be a real problem. She commented that Ib occasionally found it difficult to understand Erik's difficulties because he did not have anxiety problems himself.

\section{Treatment Goals}

During the assessment interviews, as shown in the diagnoses section above, a very different picture emerged when comparing the the ADIS-P, which reflected many problems, and the ADIS-C, which showed relative few. It is possible that the parents exaggerated Erik's difficulties due to his anxiety, and that this could be partly explained by the fact that Erik was less able to do things when with his parents as compared to when with friends. On the other hand, Erik also apparently underreported his difficulties on the ADIS, whereas on the self-report questionnaires he reported some substantial anxiety problems. We decided that we would ask Erik what he wanted to achieve by following the Cool Kids program, in order to ensure that he would be motivated.

In the first session Erik was asked to circle the pictures of things he was afraid of and thought were a problem for him. He circled a picture of "war" and "dentist" in his workbook. Additionally, when asked to complete a series of sentences related to his anxiety he wrote down the following (responses in italics):

Being anxious stops me from...getting my head under water and swimming.

Being anxious makes me feel bad because...my stomach hurt.

If I was no longer so anxious what would be different? What could I do? Everything.

Where could I go and how would I feel? I would feel nice.

Parents were also asked to fill out a series of incomplete sentences in their workbooks:

What would you like your child to be able to do which he currently doesn't because of anxiety?

Be able to transport himself, go from one place to another on his own.

That he is not afraid that others want to harm him.

What would you like him not to do? How often does he do these things now?

Think negative thoughts (1-4 times a week).

Goals that you would like to achieve.

Gain knowledge on how we should handle him. 
A "Cool Kids" Cognitive-Behavioral Therapy Group for Youth with Anxiety Disorders:

Part 1, The Case of Erik

I. Lundkvist-Houndoumadi \& M. Thastum

Pragmatic Case Studies in Psychotherapy, http://pcsp.libraries.rutgers.edu

Volume 9, Module 2, Article 2, pp. 122-178, 06-26-13 [copyright by authors]

Erik wrote down many different areas of difficulty in his workbook. After looking at the parents' goals and talking with Erik, we decided that the first treatment goal would be to help Erik learn to be able to get to places on his own, as this was the most problematic thing in everyday life, both for him and for the family as a whole. We also wanted to give Erik and his family some tools so that they could manage Erik's fears and worries better. A more detailed description of the Treatment Plan will be presented in the following section.

\section{CASE FORMULATION AND TREATMENT PLAN}

\section{Case Formulation}

Erik's case formulation is summarized in Figure 2. A number of personal predisposing factors (Box 1) made Erik vulnerable to the development of anxiety, including biological (genetic vulnerability revealed by a number of family members suffering from anxiety) and psychological factors (inhibited temperament and low self-esteem evidenced by self-ratings on the self-concept subscale of BYI).

Contextual predisposing factors (Box 2) included Erik’s early exposure to family problems like maternal anxiety and a threat-sensitive family culture. When Erik was nine years old a number of changes occurred in his life (his father left home for some weeks and he changed schools) that could have functioned as precipitating factors (Box 3), triggering the onset of his anxiety problems (Box 4).

Erik’s anxiety problems may have been maintained via a number of personal and contextual maintaining factors (Box 5). The therapists should be alert to Erik's learning difficulties and his strategies of avoiding feared stimuli (e.g., not going to the dentist), approaching feared stimuli but withdrawing before anxiety subsides, adopting a threat- and danger-oriented cognitive set, exhibiting external hypervigilance, and misinterpreting neutral events as threatening (e.g., people with another ethnic background would be feared as potential kidnappers). In addition to psychological factors, contextual maintaining factors ought to be addressed in therapy, including those related to the family system inadvertent modelling and reinforcement of threat sensitivity, hypervigilance, and avoidant behaviour), that may be reciprocally related to parental factors (maternal anxiety and an external locus of control) as well as other social network factors. The mother's anxiety probably maintained Erik's anxiety, via her overprotective behaviors and lack of coping skills that she could teach to Erik. During therapy some social network factors also became apparent, namely bullying in school and Erik's relationship to the municipally appointed contact person. Erik had told his parents that he did not want to get too much better through the program, because he did not want them to take Peter (the contact person) away from him. It seemed that Erik was gaining some positive consequences from being anxious and thus was not fully motivated to change his behavior.

A number of personal protective factors (Box 6) were identified that could prevent further deterioration and have implications for prognosis. These included psychological factors (good physical health and social skills) and contextual protective factors that were present in the treatment system (the family accepted there was a problem and was committed to resolve it), the family system (secure parent-child attachment and clear family communication), parental factors 
A "Cool Kids" Cognitive-Behavioral Therapy Group for Youth with Anxiety Disorders:

Part 1, The Case of Erik

I. Lundkvist-Houndoumadi \& M. Thastum

Pragmatic Case Studies in Psychotherapy, http://pcsp.libraries.rutgers.edu

Volume 9, Module 2, Article 2, pp. 122-178, 06-26-13 [copyright by authors]

(good adjustment), and social support network factors (parents mentioned that they had a very strong family network and appeared very motivated to help Erik).

\section{Treatment Plan}

The treatment plan for Erik's case was based on the Cool Kids Program, which was followed as a guideline, and the case formulation for Erik was conceived in that same framework.

\section{Erik's Motivation}

In the beginning it was important to motivate Erik for therapy, as he seemed a bit reluctant to talk about his anxiety and had stated that he did not want to get "too much" better. The nature of his GAD, which seemed to be the principal diagnosis, made it difficult to identify specific fears. We believed that Erik's inability to go places alone was a big handicap for him and he would therefore be motivated to change this fear. As a result we decided that this particular presentation of his symptoms was the right place to start targeting the interventions.

\section{Cognitive Restructuring}

After identifying the central areas where Erik's anxiety manifested itself, we planned to try and identify his worrisome thoughts. With this information, we would be able to do cognitive restructuring with Erik, helping him start generating alternative thoughts that were more realistic and not as anxiety provoking. It was hoped that Erik's cognitive difficulties would not be a big problem, as he was in a therapy group with younger children and was expected to learn cognitive restructuring at the same rate as the other children.

\section{$\underline{\text { Exposures }}$}

Next, we planned to focus on getting Erik to do exposure exercises, making sure he did not avoid them and stayed in the situations long enough for the anxiety to subside. This was expected to be the most important component in the treatment. It was believed that cognitively restructuring the situations would make them appear less anxiety provoking and thus more manageable to Erik. He would realize that the situations he feared were not so dangerous and that he could master them, altering his cognitive schemas concerning danger and vulnerability, and enhancing his self-confidence.

\section{Altering Maintaining Factors in the Family}

Throughout therapy we planned to involve the family in the therapy process in order to alter some of the processes maintaining Erik's anxiety. First, Mia's anxiety issues needed to be addressed by providing psychoeducation and talking about child management techniques. Furthermore, we hoped to get Ib involved in therapy, as a triangle may have formed between Erik, Mia and the anxiety, leaving Ib, who did not suffer from anxiety, out of that special relationship. At the time, Erik's anxiety seemed to be the focal issue for discussions with the extended family. The mother's niece was given the same diagnoses as Erik, and Mia had 
A "Cool Kids" Cognitive-Behavioral Therapy Group for Youth with Anxiety Disorders:

Part 1, The Case of Erik

I. Lundkvist-Houndoumadi \& M. Thastum

Pragmatic Case Studies in Psychotherapy, http://pcsp.libraries.rutgers.edu

Volume 9, Module 2, Article 2, pp. 122-178, 06-26-13 [copyright by authors]

commented on how helpful it was to speak with her sister about their children's anxiety problems. As a consequence of the therapeutic intervention, we hoped to change the family's narrative concerning Erik as an anxious boy, provide them with coping tools, and enhance the family's feeling of togetherness.

\section{COURSE OF THERAPY}

The Cool Kids Program as implemented in the Children's Anxiety Clinic at Aarhus University was conducted in a group format with 6 children, in which every child was paired with one or two student therapists. The group in which Erik took part included 5 other children. Three of them suffered from specific phobia: two girls (aged 8 and 9) who suffered from specific phobia (animal type) and were afraid of dogs, and a boy diagnosed with specific phobia (situational type), who feared being home alone and sleeping alone_-a fear that appeared after his house had been burglarized. The other two in Erik's group were eight-year-old boys suffering from multiple anxiety disorders: one was diagnosed with GAD, SAD, and social phobia; and the other with GAD, $\mathrm{SAD}$, and specific phobias, situational type (darkness) and natural environment type (lightning, thunder). For more details about these other five group members, their course of therapy, and their outcomes, see Lundkvist-Houndoumadi and Thastum's (2013) case study article that is in the same PCSP issue as this one.

\section{Structure of the Therapy}

The families met on a weekly basis for ten sessions, each session lasting two hours. Follow-up interviews were conducted 3 months and 15 months after the conclusion of treatment. A detailed description of the content of each session is presented in Table 4. Generally, all sessions used a combination of group and individual work and proceeded along the following steps:

1. The families gathered in one room and each family spoke with the student therapist assigned to them about what they had accomplished during the previous week, as well as possible problems they may have had while implementing the homework.

2. The senior psychologist and Clinic Director (the second author) introduced the goal for the overall session. The children and the student therapists went to another room, where the psychologist presented the content of each session based on the manual of the Cool Kids Program, using the children's workbook as a supplement.

3. The psychologist and six of the student therapists returned to the group of parents, while two student therapists stayed behind and played with the children. Parents were informed about the principles that had been presented to the children and taught alternate ways of interacting with their children using the parent's workbook of the Cool Kids Program.

4. The children came into the room and sat with their parents and student therapists. Children told their parents what they had learned. Along with the parents and student therapists, the children helped decide on the assignments for the following week. 
A "Cool Kids" Cognitive-Behavioral Therapy Group for Youth with Anxiety Disorders:

Part 1, The Case of Erik

I. Lundkvist-Houndoumadi \& M. Thastum

Pragmatic Case Studies in Psychotherapy, http://pcsp.libraries.rutgers.edu

Volume 9, Module 2, Article 2, pp. 122-178, 06-26-13 [copyright by authors]

The structure of the Cool Kids Program is presented in Table 7, which shows: the type of meeting (assessment, therapy, follow-up); the type of segment (whether it was attended by parents, children or both); the number of individuals (children, clients, parents, student therapists and senior psychologists) who were present at the meetings; and whether Erik and his parents attended these meetings. It should be noted that two components were added to the original program shown in Table 7. The family was offered the option of one house visit, the timing of which was decided through consultation with the parents. In addition, Session 8 was conducted in a shopping mall, where exposure exercises were implemented.

\section{Session 1-3}

In the first sessions of the Cool Kids Program, children and their families are taught about anxiety and how thoughts are linked to feelings. After the children are able to identify the thoughts that make them anxious, they are coached in detective thinking (cognitive restructuring). Additionally, parents are informed about child management techniques.

\section{Identifying the Anxiety Problems and the Underlying Thoughts}

In the first session all children in the group were asked to complete some exercises in their workbooks, with the aim of providing them with a better understanding of their anxiety. Erik had difficulties completing his first homework assignment, for which he was asked to write down what he was thinking and feeling in a situation in which he felt worried. He claimed he had not been afraid in any situation, though Mia described two situations in which he had been afraid. The first one was when Erik phoned her after some children he was walking with had run away, leaving him alone. According to Mia, Erik said he was afraid to walk the rest of the way to school alone. When she reminded him of the incident he denied being afraid in that situation and could not think of anything to write down in his workbook. The second situation referred to Mia's subsequent efforts to challenge him by asking him to go to the shopping mall and buy something. Erik did not want to, saying it was late in the evening. We encouraged and helped Erik to fill out the remaining boxes in the workbook. Erik wrote down the following situations (the first was completed in the session when Erik was introduced to the exercise):

\begin{tabular}{|l|l|l|l|}
\hline What happened? & $\begin{array}{l}\text { What was I } \\
\text { thinking? }\end{array}$ & $\begin{array}{l}\text { What was I } \\
\text { feeling? }\end{array}$ & $\begin{array}{l}\text { How worried was } \\
\text { I? (scale of 0-10) }\end{array}$ \\
\hline I was assaulted. & They will kidnap me. & I was scared. & 9 \\
\hline $\begin{array}{l}\text { I had to go to the } \\
\text { shopping mall } \\
\text { alone. }\end{array}$ & $\begin{array}{l}\text { It was late in the } \\
\text { evening (18.00 o } \\
\text { clock). }\end{array}$ & I was disappointed. & \\
\hline $\begin{array}{l}\text { My friends were } \\
\text { going away and [I] } \\
\text { was left alone. }\end{array}$ & I'm going back. & & \\
\hline
\end{tabular}

When Erik completed the exercises in his workbook, it became apparent that he felt the need to create a story in order to explain the reasons behind his fears. 
A "Cool Kids" Cognitive-Behavioral Therapy Group for Youth with Anxiety Disorders:

Part 1, The Case of Erik

I. Lundkvist-Houndoumadi \& M. Thastum

Pragmatic Case Studies in Psychotherapy, http://pcsp.libraries.rutgers.edu

Volume 9, Module 2, Article 2, pp. 122-178, 06-26-13 [copyright by authors]

\section{Cognitive Restructuring}

Children are taught cognitive restructuring, i.e. detective thinking, or learning to think as a detective who asks questions, in order to find proof for their worrisome thoughts. Children are asked to find a fellow detective who will help them in the process and Erik chose Peter - an adult who was assigned to Erik by the municipality — to be his detective, indicating that he looks up to Peter.

It was difficult to complete the activities related to detective thinking, as Erik once again claimed that he was afraid of nothing. He was instead asked to try and imagine that he was in an anxiety-provoking situation. Erik had to look in his book in order to find detective questions to ask and had difficulties assisting others with the exercises when the children worked in pairs. Furthermore, he needed a lot of time to write down the exercises, and his handwriting and spelling were very poor for his age. When he was later asked to explain to his parents what detective thinking was and which detective he chose, he could not answer.

Below are three situations completed in Erik's workbook on the Detective Working Sheets. The first one was partly completed in the first session that detective thinking was introduced. The second situation was the only situation Erik had completed as part of his homework assignment, and the third situation was completed with the help of student therapists in the second session of cognitive restructuring.

\begin{tabular}{|c|c|c|c|}
\hline $\begin{array}{l}\text { Event: What is } \\
\text { happening? }\end{array}$ & $\begin{array}{l}\text { Thoughts: What am } \\
\text { I thinking? }\end{array}$ & $\begin{array}{l}\text { Detective questions: } \\
\text { What is the evidence? } \\
\text { What else could } \\
\text { happen? } \\
\text { What happened when } \\
\text { I worried at an earlier } \\
\text { time? } \\
\text { What is likely to } \\
\text { happen? }\end{array}$ & $\begin{array}{l}\text { What is my } \\
\text { realistic thought? }\end{array}$ \\
\hline My mother is late. & $\begin{array}{l}\text { She has had a car } \\
\text { accident. }\end{array}$ & $\begin{array}{l}\text { There is almost no } \\
\text { traffic. } \\
\text { I'll try and wait a bit. } \\
\text { I could call her. }\end{array}$ & \\
\hline $\begin{array}{l}\text { The swine flu might } \\
\text { come to Denmark. }\end{array}$ & People die from it. & $\begin{array}{l}\text { I heard about it on TV. } \\
\text { Few people die from it. } \\
\text { It spreads to the whole } \\
\text { world. } \\
\text { I saw the news with my } \\
\text { parents and got very } \\
\text { worried. } \\
\text { The influenza will die }\end{array}$ & $\begin{array}{l}\text { If it comes to } \\
\text { Denmark we will } \\
\text { have enough } \\
\text { medicine for } \\
\text { everyone that is } \\
\text { sick. }\end{array}$ \\
\hline
\end{tabular}


A "Cool Kids" Cognitive-Behavioral Therapy Group for Youth with Anxiety Disorders:

Part 1, The Case of Erik

I. Lundkvist-Houndoumadi \& M. Thastum

Pragmatic Case Studies in Psychotherapy, http://pcsp.libraries.rutgers.edu

Volume 9, Module 2, Article 2, pp. 122-178, 06-26-13 [copyright by authors]

\begin{tabular}{|l|l|l|l|}
\hline & & $\begin{array}{l}\text { out on its own. } \\
\text { Most people have been } \\
\text { cured. }\end{array}$ & \\
\hline $\begin{array}{l}\text { Scout camp (walking } \\
\text { on a path alone) }\end{array}$ & $\begin{array}{l}\text { Someone might } \\
\text { assault me. }\end{array}$ & $\begin{array}{l}\text { I haven't been attacked } \\
\text { before on that road. } \\
\text { The path is peaceful. }\end{array}$ & $\begin{array}{l}\text { The likelihood it } \\
\text { might happen is } \\
\text { small. }\end{array}$ \\
\hline
\end{tabular}

When we started talking with Erik about the swine flu he claimed that he was not afraid of it anymore, because Ib had told him that there is a pill that cures it. After asking him about the thought that made him worried, it became clear that he was concerned that his parents might die from it. It was difficult for Erik to find detective-type questions and explain why he was afraid of walking on the path alone. Finally, he said that he was carrying a lot of things and if someone attacked him it would be difficult for him to get away.

\section{$\underline{\text { Familial Influences }}$}

Although Erik claimed not to be afraid of anything, Mia told us that he was afraid of being kidnapped. When she had tried to talk to her son about his fear, he told her: "When one day it happens, then you can go and tell all those psychiatrists and psychologists: What did I tell you?!" On their way to one of the sessions Mia pointed to a child (from another ethnic background) walking alone on the sidewalk and asked Erik how that child could walk on his own without being kidnapped. Erik then replied: "He is one of their own and they have arrangements among them.” We encouraged her to do detective thinking with Erik instead of dismissing his anxiety or trying to reassuring him that nothing would happen.

Ib generally seemed disengaged in the first sessions and did not take part in the conversations. When presented with the parents' homework assignments, he handed them to Mia. We encouraged him to help Erik with his homework, mentioning studies that indicate that fathers may have a positive influence on the treatment of their children's anxiety.

The psychologist introduced the parents to some child management techniques and talked about how parents of anxious children have a tendency to overprotect them. When he asked the parents if they thought they were overprotective, Mia described how she reacted when Erik told her that he would like to try to go somewhere by himself: "I told him, 'Then you can call me when you get there and I can call you when I finish from work.’”

\section{Session 4 and House Visit}

The aim of Session 4 was to introduce the principles of exposure by starting to develop relevant hierarchies, while still practicing detective thinking. Erik was sick, but Ib came to the session, and we also arranged a house visit before session 5. 
A "Cool Kids" Cognitive-Behavioral Therapy Group for Youth with Anxiety Disorders:

Part 1, The Case of Erik

I. Lundkvist-Houndoumadi \& M. Thastum

Pragmatic Case Studies in Psychotherapy, http://pcsp.libraries.rutgers.edu

Volume 9, Module 2, Article 2, pp. 122-178, 06-26-13 [copyright by authors]

\section{Cognitive Restructuring}

At the fourth session, Ib described how Erik had made progress, going home from school with his brother a couple of times. However, Erik got very upset when he was asked to complete a detective thinking worksheet with them after the following episode:

Erik's parents asked him to go to the store close to their house (approximately 200 meters away). They were standing on the balcony and could see the first 100 meters of the path. They saw a car driving down the road and when it reached the end of the road it turned and stopped. Erik stopped walking immediately, turned around and walked home. When he came back, his parents encouraged him to complete a detective thinking sheet. They tried to explain that the car belonged to those who live in the house at the end of the road. The following was written down in Erik's workbook:

\begin{tabular}{|c|c|c|c|}
\hline $\begin{array}{l}\text { Event: What is } \\
\text { happening? }\end{array}$ & $\begin{array}{l}\text { Thoughts: What am } \\
\text { I } \\
\text { thinking? }\end{array}$ & Detective questions & $\begin{array}{l}\text { What is my realistic } \\
\text { thought? }\end{array}$ \\
\hline $\begin{array}{l}\text { On my way to the } \\
\text { shop with my brother } \\
\text { comes a car with } \\
\text { immigrants. }\end{array}$ & $\begin{array}{l}\text { Earlier episode } \\
\text { where some men } \\
\text { followed me and my } \\
\text { friend. I got scared } \\
\text { and turned around to } \\
\text { go home. }\end{array}$ & $\begin{array}{l}\text { No clues that they } \\
\text { would kidnap me. } \\
\text { Those in the car live } \\
\text { in the house there. } \\
\text { Nothing has } \\
\text { happened when I } \\
\text { have been worried } \\
\text { before and probably } \\
\text { nothing would have } \\
\text { happened this time. }\end{array}$ & $\begin{array}{l}\text { When I got home my } \\
\text { mother told me that } \\
\text { the persons in the } \\
\text { car have bought the } \\
\text { house across the } \\
\text { street. }\end{array}$ \\
\hline
\end{tabular}
thinking:

Ib raised his concerns regarding the way Erik responded to their efforts to apply detective

I think we were too hard on him when we tried to do the detective thinking. He couldn't put words on what it was he was afraid of, and after we asked him a lot of questions... We asked him what is the evidence for this he is afraid of? But of course he doesn't have any evidence: "But where can you feel it? In your hands? Where?" Then he yelled: "I don’t know!" And he started crying. He gets sad because he wants to answer us but he can't and we, of course, got also very sad about it.

They wanted to have something they could present to the group, and Ib thought they should take it more slowly from now on. Ib’s impression was that Erik had difficulties expressing his anxiety with words. Furthermore, he commented that Erik did not really want to come to the Children's Anxiety Clinic, because he had been assessed by psychologists, doctors, and psychiatrists for many years, and was tired of it: 
A "Cool Kids" Cognitive-Behavioral Therapy Group for Youth with Anxiety Disorders:

Part 1, The Case of Erik

I. Lundkvist-Houndoumadi \& M. Thastum

Pragmatic Case Studies in Psychotherapy, http://pcsp.libraries.rutgers.edu

Volume 9, Module 2, Article 2, pp. 122-178, 06-26-13 [copyright by authors]

He just really wants to get rid of his anxiety. He said, for example, the other day: "I will never get a girlfriend because I am such a wimp." What motivates him to continue is that he desperately wants to be able to do the same things as his friends. The other day he was really sad because he thought about this [that he can't do the same things as the others]. The defeats he experiences really bother him.

At the house visit we talked with Erik about how detective thinking was meant to help him in order do the exposure exercises. We said that, if it was too difficult and he did not think it helped him, he did not have to complete the detective thinking exercises, as long as he would do the exposures we were about to plan together.

\section{Familial Influences}

Ib seemed much more engaged in the fourth session, when he came without Mia or Erik and seemed to understand the principles of exposure. The same was observed in the home visit, when Ib participated actively in the conversation for the first time and offered to help Erik with the exposure exercises. It was also obvious that Erik preferred doing the exercises with his father. He mentioned an occasion when they had been to a zoo and he had touched a snake that his father did not dare touch, saying that "It was cool I could do something Dad couldn’t.”

In the house visit, we also had the chance to address Mia's anxiety problems, as they were influencing Erik negatively. Mia said that she was anxious because her son was planning to go to a theme park with some friends. She was worried that, since he did not like to ride the more "wild" carousels, he would be left alone by the others. She told Erik that he could call her if he was alone and got scared. Other occasions when she was concerned about her son also came up in the discussion. Although she said she trusted him and he would not do anything stupid (because his anxiety would hold him back), she was worried. We tried talking with her about how overprotective she was and how taking all these precautions around Erik resulted in her communicating to him that the situation was dangerous. She seemed to accept that she should talk with other adults if she was anxious and she appeared to understand her role in exacerbating Erik's anxiety, stating that she was very willing to try and change her behavior. Ib was glad we talked about these things, because he also thought that she was overly worried and overprotective of Erik.

\section{$\underline{\text { Exposures }}$}

The principles of exposure were presented to the father in Session 4, and guidelines for making a stepladder were explained. The ladder consists of a series of increasingly difficult steps in confronting fears, as well as the rewards to be given to the child after each step has been conquered. Such a stepladder was constructed with the assistance of co-therapists, with a primary aim of getting Erik to gradually walk longer distances from home, at first with his brother and later alone.

In the house visit, we started out by talking with Erik about how Ib had mentioned that he was a bit tired of "all those psychologists." Erik explained that he had been tested for his learning difficulties at school and he had missed classes because of it. He also thought it was annoying 
A "Cool Kids" Cognitive-Behavioral Therapy Group for Youth with Anxiety Disorders:

Part 1, The Case of Erik

I. Lundkvist-Houndoumadi \& M. Thastum

Pragmatic Case Studies in Psychotherapy, http://pcsp.libraries.rutgers.edu

Volume 9, Module 2, Article 2, pp. 122-178, 06-26-13 [copyright by authors]

that he was the eldest in the group, and he disliked the way the psychologist talked to them "as if we are young children." Nevertheless, he realized that this was because the other children in the group were younger. We praised him for having the courage to talk to us about his feelings and we asked for his permission to talk with the psychologist about it.

Erik told us that he had once again tried to walk to the shop with his brother and had managed to do so without any problems. When asked about how the experience had been, he replied that it was not hard, because they had been talking the whole way. He had also been to a shopping mall with his brother and learned to ride a bike. He received a lot of praise and it was obvious that he was proud of himself and thought that he had made a lot of progress. This seemed to motivate him more for the work we did in creating a stepladder with the end goal of Erik walking to his friend's house alone.

\section{Sessions 5-7}

These sessions aimed to consolidate and problem-solve the implementation of stepladders. Session 7 took place at a shopping mall, where exposure exercises were also completed. The student-therapists observed how parents coached their children and assisted them if needed.

\section{$\underline{\text { Exposures }}$}

A stepladder was made with increasingly difficult steps involving Erik cycling or walking to different places (first in the company of others and then alone at different times of the day). Erik successfully completed all of the steps in which he was supposed to go places by bike, reaching his end goal very quickly. He thought it was silly advancing gradually up the stepladder by walking short distances and so took bigger steps up the ladder than originally planned. It is possible that he thought that others would think he would look funny walking back and forth for short distances, and his social phobia may have pushed him into doing more. Erik and his parents seemed very proud of the progress he had made. Nevertheless, it was noticed that he had skipped all the steps involving him walking on his own, and it seemed difficult to motivate him to make a stepladder involving him walking to places.

When we met with Erik and his parents in the shopping mall in session 7, we had thought about encouraging Erik to do things related to his social phobia. It quickly became obvious that Erik did not want to participate and was very negative about doing the things that we, along with the parents, suggested. After a while, we managed to make a stepladder starting at very easy tasks, including buying things in stores. It became obvious that it was very difficult for Erik to concentrate on what we told him. He kept forgetting which CD he was meant to ask about and wanted to know exactly what he should say.

When Erik completed the first step, he said it had gone "badly." However, when we asked him to describe what happened, it seemed that he had done the step as agreed beforehand. Erik might have thought it had gone badly because he did not feel well physically. He tried to argue that it was not important for him to learn to do these things now and that it would be more 
A "Cool Kids" Cognitive-Behavioral Therapy Group for Youth with Anxiety Disorders:

Part 1, The Case of Erik

I. Lundkvist-Houndoumadi \& M. Thastum

Pragmatic Case Studies in Psychotherapy, http://pcsp.libraries.rutgers.edu

Volume 9, Module 2, Article 2, pp. 122-178, 06-26-13 [copyright by authors]

relevant when he got older. After we encouraged him and praised his accomplishment, he agreed to do the next step.

Afterwards he seemed much happier and came up with the idea of going and buying a present for his mother. We asked him if he wanted to go to the clerk in the shop and ask her if she would help him find a present to his mother. Erik was once again negative and did not want to do the task, but ultimately agreed to take the step after commenting, "It doesn't look like I have a choice." After observing Erik for a while, it became obvious that he had no intention of approaching the clerk in the shop. We reminded him of the step, but he said he could not do it. He claimed it was because he had a stomachache that was unrelated to his anxiety. We talked with him about how hard it can be being anxious but how good he would feel if he managed to complete the step, even though he had a stomach ache. We reminded him of all the things he had achieved until then, we tried to do cognitive restructuring with him and presented ideas about smaller steps he could do. Ultimately, he agreed to go to the shop with me and I would buy the present for his mother. While in the shop he apologized that he had not managed executing the designed step.

\section{$\underline{\text { Familial Influences }}$}

In Session 5, Mia mentioned that when Erik would come into her room, her first reaction was: "What is wrong?" She acknowledged that it was an undesirable reaction, and Erik had commented that it bothered him. She was encouraged to do some cognitive restructuring on her own fears. Furthermore, she was encouraged not to reassure Erik as much and inform him that altering her behavior would be a form of exposure so that he would stop depending on her.

When we were in the shopping mall talking with Erik about the exposures, Mia seemed very critical. She said that she could understand Erik's fears about being alone, because she also had trouble with it, but she became irritated when she realized how difficult it was for Erik to talk to a salesperson about something. Mia told us that she generally did not feel she had the energy to be there for Erik right now and mentioned she had been fired from her job. We decided that she should not participate in the exposures. Ib was very good in assisting Erik in the exposures in the shopping mall, and said he thought it was great that we did these exercises, since Mia and he had given up and never expected him to do such things.

\section{Sessions 8-10}

The aim of the last sessions was to discuss social skills and teach the children assertiveness while continuing to work through the stepladders. Relapse management and future plans were discussed in the last session and the children's graduation as “cool kids” was celebrated. A discussion concerning a review of Erik’s progress in therapy will be presented in section 8 below as part of an evaluation of the therapy.

\section{$\underline{\text { Exposures }}$}

Erik thought that it was silly to do gradual steps from stepladders and said he preferred just doing large things when he was in the mood for them. We talked about making agreements 
A "Cool Kids" Cognitive-Behavioral Therapy Group for Youth with Anxiety Disorders:

Part 1, The Case of Erik

I. Lundkvist-Houndoumadi \& M. Thastum

Pragmatic Case Studies in Psychotherapy, http://pcsp.libraries.rutgers.edu

Volume 9, Module 2, Article 2, pp. 122-178, 06-26-13 [copyright by authors]

so that we could check whether he had completed the exposures and that it could be part of stepladders with few steps. Then Erik wanted to tell us about what he had achieved in the past week. It became clear that he had planned beforehand in which order he wanted to tell his accomplishments, depending on his perception of the relative impressiveness of the steps.

Erik looked very proud when he told us how he and his brother had been in a shop. When they could not find what they wanted, Erik went to the shop assistant and asked about it. He also reported that he had stayed home by himself and waited for Mia while she went shopping. Furthermore, he had been to the dentist and, when he became nervous in the waiting room, his mother had helped him by doing some detective thinking that helped his anxiety subside. Erik had also tried to stay home alone while his parents had gone shopping and had gone to his friend's house on foot. When we commented how impressive all this was he said: "That's nothing. That's normal!”

\section{$\underline{\text { Social Skills }}$}

As part of the social skills training, a role play was completed in the session with the children. Erik said he was a "push puppet" in school and talked about how other children would push him around in school and make him do things he did not want to do. He ended up doing the things because he did not seem to know how to stop this bullying. This bullying at school might also have contributed to the maintenance of his anxiety, feeding his feelings of low self-esteem. Erik was advised to talk with his teacher and parents about it and encouraged to try and be assertive in different role plays.

Erik seemed to enjoy the role plays, although he had trouble coming up with replies. He forgot what he was supposed to say and claimed that it was hard because the others always had a better reply/argument related to what he said. He was encouraged to look more assertive (looking others in the eyes, standing up straight, talking loud, etc.) and he gradually seemed to gain confidence. Erik was very active and engaged in the social skills activities, possibly finding them particularly relevant due to his difficulties at school. He may have found role playing to be easier to execute, as he was not expected to sit down and concentrate on writing.

\section{$\underline{\text { Familial Influences }}$}

Mia had made progress in urging Erik to do more things. When Erik said he was hungry and wanted something to eat, she told Erik and his brother that they had to buy something to eat on their own. She explained that Erik had come out of the shop and expressed his surprise that the clerk had been very kind. While asking Erik if he had done any exposures since the previous session, Mia started talking about how she almost did not see Erik because he was always with friends doing things. I asked Erik if he had done anything that was difficult for him and he could not think of anything. It did not seem that they had done any organized work at home with exposures, although Erik mentioned that he had walked to a friend's house. 
A "Cool Kids" Cognitive-Behavioral Therapy Group for Youth with Anxiety Disorders:

Part 1, The Case of Erik

I. Lundkvist-Houndoumadi \& M. Thastum

Pragmatic Case Studies in Psychotherapy, http://pcsp.libraries.rutgers.edu

Volume 9, Module 2, Article 2, pp. 122-178, 06-26-13 [copyright by authors]

\section{THERAPY MONITORING AND USE OF FEEDBACK INFORMATION}

Although no systematic gathering of quantitative data took place, the weekly supervision sessions proved very valuable for monitoring the course of treatment. Under the supervision of the director of the Clinic (the second author), all student therapists had the opportunity to share observations and reflections with respect to their own and others' cases and resolve issues as they came up.

In the first sessions we were concerned about how we could help Erik with his anxiety, since he did not admit to any such feelings and did not tell us about the situations that made him fearful. After raising our concerns in supervision, we decided to try and reformulate situations so that instead of "feared" they were referred to as "difficult" for him. We did not ask him if he was "afraid," as it seemed that he reacted on the words "afraid" and "worried" as very negative terms. This approach proved to be successful.

Additionally, we decided to revise our treatment plan concerning the cognitive restructuring of Erik's worrisome thoughts following a discussion in supervision that raised the issue of Erik's cognitive difficulties, which we deemed central to his inability to learn "detective" thinking. This decision was also influenced by the problems we experienced with Erik's lack of motivation, as well as his father's reports that Erik had started crying when he felt pressured and unable to respond to guiding questions posed by his parents when doing detective thinking. We thought it was important not to push Erik too much when teaching him detective thinking exercises. Instead, we shifted our focus to exposure assignments that were not cognitively demanding. We hoped that these assignments would also prove more motivating for Erik, as he was interested in learning to be able to go to places alone. This turned out to be the case, as he made impressive progress in the stepladders.

After Erik’s social phobia became obvious in the in-vivo session (shopping mall), we decided to encourage the family to work on that. Despite some setbacks, which can be attributed to his mother's overprotective behavior and Erik's reluctance to accept his social fears, no additional revisions were made to the treatment plan. In addition, in supervision we occasionally were informed about how Erik was doing in his school, as one of the student therapists was a substitute teacher at Erik's school. She informed us that he had told his class about the program and his positive feelings toward it and that he had successfully participated in a school play and received positive comments about the changes he had made.

\section{CONCLUDING EVALUATION OF THE THERAPY'S PROCESS AND OUTCOME}

\section{Quantitative Evaluation of Outcome with the ADIS-P}

Erik's diagnoses at the different points in time can be seen in Table 6. Erik didn't fulfill the criteria for any diagnosis at the 3-month and 15-month follow-up sessions. Ib commented at the 3-month follow-up that Erik's worries had gotten $80 \%$ better overall, and some worries had disappeared completely. He was still not happy about buying things, but Mia said she continued 
A "Cool Kids" Cognitive-Behavioral Therapy Group for Youth with Anxiety Disorders:

Part 1, The Case of Erik

I. Lundkvist-Houndoumadi \& M. Thastum

Pragmatic Case Studies in Psychotherapy, http://pcsp.libraries.rutgers.edu

Volume 9, Module 2, Article 2, pp. 122-178, 06-26-13 [copyright by authors]

to pressure him to buy the things he wanted on his own. Ib explained that Erik had experienced a big setback when Mia had forgotten her mobile phone and Erik could not get in contact with her. After that episode, he had trouble staying home alone and was concerned that something bad might happen to his mother. Erik did not fulfill the criteria for Separation Anxiety Disorder, as the parents did not think that he was afraid that something bad would separate him from them (e.g., kidnapped). They said that he rode his bike as fast as he could and did not like walking alone, but he no longer talked about any worries. This may have been due to Erik feeling less overwhelmed by worries as a result of his demonstrated ability to manage his anxiety on his own.

In the 3-month follow-up session, Mia mentioned an incident when she was stung by a bee and Erik calmed her down. She also noted that he no longer avoided going to the dentist. It appeared that Erik's specific phobias had subsided. The questions related to the social phobia and assertiveness revealed some situations in which Erik was concerned about what others would think about him and he still had difficulty saying "no" to others in school. His parents thought that these behaviors were part of being a teenager and were not problematic for Erik. Ib also mentioned that Erik had flirted with a girl during the summer and had said he wanted to try drinking alcohol. The parents talked about having other issues that they needed to address concerning Erik as he got older.

As mentioned above, at the 15-month follow-up assessment, no diagnosis was given to Erik, based on an assessment done using the ADIS-P. When the parents were asked whether Erik was afraid of anything, the mother explained:

He is unable to take the bus to get home so we have to pick him up [the family had moved since our last meeting]. There is continuous progress but he still has trouble with transporting himself to places. He has never tried to take the bus alone. Something always comes in the way and I can't really tell if it is coincidental...He handles things much better if he gets hurt. He is a little bit anxious about many things, but it is very little compared to how it was. It is not something that takes up space in the family. He also has his own money and goes to the stores, buying things on his own now, and can stay home alone without any problems.

Overall, the quantitative data indicated a positive effect of therapy, as indicated by multiple self-report measures and two follow-up diagnostic interviews. These assessments suggest that Erik remained diagnosis-free after treatment.

\section{Quantitative Evaluation of the Therapy on the Self-report Questionnaires}

The results on the standardized self-report measures completed by Erik and his parents are presented in Table 5. The measures include:

- Strengths and Difficulties Questionnaire (SDQ)

- Beck Youth Inventories of Emotional and Social Impairment (BYI)

- Spence Children's Anxiety Scale (SCAS)

- Children's Anxiety Life Inference Scale (CALIS): 
A "Cool Kids" Cognitive-Behavioral Therapy Group for Youth with Anxiety Disorders:

Part 1, The Case of Erik

I. Lundkvist-Houndoumadi \& M. Thastum

Pragmatic Case Studies in Psychotherapy, http://pcsp.libraries.rutgers.edu

Volume 9, Module 2, Article 2, pp. 122-178, 06-26-13 [copyright by authors]

Note that with two exceptions, all the scales are scored in a negative direction, that is, the higher the score the more psychopathology. The exceptions, which are scored in the opposite way, are the Prosocial Behavior scale of the SDQ and the Self-Concept scale of the BYI.

The numbers in the table include the following notations concerning the nature or size of the change for the measure indicated over time:

* clinical population level, i.e., that the number is at a level that falls within the clinical population. \# statistically significant change.

a large effect, i.e., positive change that is more than one standard deviation of the scale.

blue print: clinical change (going from a clinical to a non-clinical level on a scale over time). red print: negative change, i.e., change over time in a more psychopathological direction.

The number in the table also includes the following notations indicating the comparison point for the number:

a pre-treatment, i.e., compared with pre-treatment.

b post-treatment, i.e., compared with post-treatment.

c 3 -month follow-up, i.e., compared with 3-month follow-up.

The results on the self-report measures are graphically shown in Figures 3-12.

Overall, the results in Table 5 and Figures 3-12 indicate (a) that Erik had made significant changes on the items related to his anxiety problems on most of the parent and child questionnaires, and (b) that Erik had maintained his progress 3-months and 15-months posttreatment. In some cases, additional progress was observed after treatment ended. This suggests that the family had obtained some useful tools to keep working on Erik's anxieties. Below we describe more details about these changes as reflected in Table 5.

Strengths and Difficulties Questionnaire (SDQ)

On the basis of both parents' reports, Emotional Symptoms present at pre-treatment were diminished with statistical significance at post-treatment and 3 months later, and remained stable at 15 months. The Total Score on Difficulties changed positively at post-treatment and 3 months after the end of treatment with statistical significance, and remained stable at 15 months. No results were able to be obtained from Erik at post-treatment, but when we compared the pretreatment scores with the scores at the 3-month follow-up meeting, Emotional Problems showed a large negative effect. However, at the 15-month follow-up session, the Emotional Problems and Total Score on Difficulties had changed positively with statistical significance.

Beck Youth Inventories of Emotional and Social Impairment (BYI)

Tracing changes in Erik's self ratings on the various subscales across the different points in time we see the following. Scores on the Self-Concept subscale remain unchanged from pretreatment to post-treatment, while they showed a statistically significant positive change at the 3 month follow-up, dropping back to the initial level at 15 months. Scores on the Anxiety subscale showed a statistically significant drop at the 3-month follow-up compared to post-treatment. 
A "Cool Kids" Cognitive-Behavioral Therapy Group for Youth with Anxiety Disorders:

Part 1, The Case of Erik

I. Lundkvist-Houndoumadi \& M. Thastum

Pragmatic Case Studies in Psychotherapy, http://pcsp.libraries.rutgers.edu

Volume 9, Module 2, Article 2, pp. 122-178, 06-26-13 [copyright by authors]

Scores on the Depression subscale showed a statistically significant drop from pre-treatment to post treatment, but increased again 3 months later and remained at the same level at 15 months post-treatment. Scores on the Anger subscale dropped significantly at 3 months when compared to post treatment and that drop was maintained at 15 months post treatment.

\section{Spence Children’s Anxiety Scale (SCAS)}

On the basis of Erik's and his parents' answers on all subscales at post-treatment and the two follow-up sessions, Erik falls within the normal/non-clinical group in all areas of functioning, with one exception. This was Erik's Anxiety About Physical Injury, for which he was only in the clinical range at post-treatment.

When comparing the pre- and post-treatment parental ratings of Erik’s functioning, the perceived change reaches statistical significance and the requirement for clinical change on Generalized Anxiety and Social Phobia subscales as well as the Total Anxiety score. Ib, who had rated Erik as having more difficulty with Obsessive-Compulsive Disorder symptoms at pretreatment, rated these symptoms as significantly lower at post-treatment.

At the 15-month follow up, the ratings were approximately the same as at the 3-month assessment, with the exception of the Separation Anxiety Disorder scale on Ib's report, which was significantly lowered.

\section{$\underline{\text { Children's Anxiety Life Inference Scale (CALIS) }}$}

Erik's parents responded differently on this questionnaire at pre-treatment. Mia gave a more elevated score at pre-treatment, indicating that Erik's anxiety interfered a lot in his life and her personal life. At post-treatment both parents gave Erik similar scores (Mia's ratings showed a statistically significant change and large effect), and they both rated low levels of difficulties at the 3 month- and 15-month follow-up assessments.

Erik's answers suggested that he perceived no great interference in his life due to anxiety at pre-treatment or post-treatment. However, his score was very high at the 3-month follow-up session, although it went down at the 15-month assessment. This will be discussed below in limitations.

\section{Limitations in the Quantitative Measures}

A number of limitations related to the quantitative measures should be taken into consideration at this point. First of all, there is a shortage of Danish standardized and validated self-report tools for assessing children with social and emotional problems (Thastum, Ravn, Sommer \& Trillingsgaard, 2009). The BYI was the only questionnaire used that has been standardized in Denmark. For the other questionnaires, we chose to use norms from other countries, with the understanding that this may result in conclusions of questionable validity, although the norms taken into consideration were based on large populations from western countries 
A "Cool Kids" Cognitive-Behavioral Therapy Group for Youth with Anxiety Disorders:

Part 1, The Case of Erik

I. Lundkvist-Houndoumadi \& M. Thastum

Pragmatic Case Studies in Psychotherapy, http://pcsp.libraries.rutgers.edu

Volume 9, Module 2, Article 2, pp. 122-178, 06-26-13 [copyright by authors]

Another limitation of this case study is that there was no third party who functioned as an independent assessor; the first author was Erik's therapist and the administrator of the ADIS and the self-report questionnaires. It is possible that the favorable results obtained may have been affected by the family's desire to please us. They were offered therapy free-of-charge and knew that the therapists were just beginning their careers. This might have made them feel pressured to report a positive result from therapy. It is also possible that the parents exaggerated Erik's anxiety problems before treatment in order to ensure they would be offered treatment.

The results obtained on the CALIS 3-month follow-up indicated that Erik believed that his anxiety was interfering to a great degree in his everyday life. This was surprising, as he had claimed that his anxiety did not interfere in his life at both pre- and post-treatment assessment. A number of possible explanations ought to be considered. It might be that Erik became more aware of his difficulties as a result of participating in the treatment program. Additionally, Mia's reduced overprotective behavior toward Erik may have forced him to manage more things on his own and consequently contributed to his belief that anxiety interferes more in his life. However, this would be expected to have appeared at the post-treatment assessment.

The third, and perhaps most likely, possibility is that this questionnaire, which was the last one handed out, was not answered carefully. One of the student therapists recorded that Erik experienced difficulties when completing the questionnaires at the three-month follow-up. He was the last one trying to complete the form when the other children had already finished and were playing. It might be that he was tired and simply did not pay much attention to the questions that were the last to be given. This final option is particularly feasible given his noted concentration difficulties.

\section{Qualitative Evaluation of the Therapy}

\section{The Parents’ Evaluation of Treatment Outcome}

In Sessions 9 and 10 a qualitative evaluation of Erik’s accomplishments in relation to treatment goals took place. The evaluation was done using a number of questions that the client's parents had to answer in the workbook (see Table 8). The parents believed that Erik's progress could be partly accounted for by the fact he was getting older. They told the other parents that they should not be worried about their children, because they would inevitably get better as they got older. The psychologist pointed out that one reason for Erik's drastically more mature appearance might be a result of his increased ability to manage things on his own.

At the 3-month follow-up, it was obvious that the parents were very happy about Erik's progress and thought he had no significant problems due to anxiety, other than those issues that were typical for children of his age. Interestingly, Mia commented that she missed Erik, because he spent less time with her and more time with his friends.

At the 15-month assessment the parents reported that they thought anxiety occupied limited space in the family life. As the mother said: 
A "Cool Kids" Cognitive-Behavioral Therapy Group for Youth with Anxiety Disorders:

Part 1, The Case of Erik

I. Lundkvist-Houndoumadi \& M. Thastum

Pragmatic Case Studies in Psychotherapy, http://pcsp.libraries.rutgers.edu

Volume 9, Module 2, Article 2, pp. 122-178, 06-26-13 [copyright by authors]

I think he spends his thoughts and energy on other things now. This [the program] has definitely helped him. I think things will slowly change because he is getting older, but I am sure he thinks about some of the things he has learned here and therefore has made progress. At school, they have also noticed that Erik has changed. He has gotten more self-confident and is better at handling situations. He has some problems with another child in his class. But now he says: "Listen here Chris, I will not talk to you if you are going to talk to me like that." I think he has more energy to think of more things than he had before. On our way up here he told me: "Mum, this may sound stupid, but I don't really think about this anxiety, since I started playing the guitar.”... But I also think that the fact that Erik has gotten more mature plays a role in this. I also think he is growing out of his anxiety. His brain is getting more reasonable.

The mother still believed that Erik's age had an effect on him becoming nearly anxiety free. It is possible that Erik matured cognitively and was better able to cognitively process situations that would have made him anxious before. Practicing detective thinking might have also contributed to this decrease in anxiety. Mia acknowledged the importance of the treatment program for Erik, as he still spoke about it at home. In addition to feeling less anxious, Erik had also become more self-confident, energetic, and motivated to start activities that interested him.

In order to find out what had changed since the beginning of therapy and determine whether the change in Erik was due to him reacting differently in anxiety-provoking situations or his parents changing their behavior, the parents were asked to describe a recent incident when Erik got anxious.

Mia: Erik called me because he had fallen and hurt himself and wanted to hear if there were bacteria in the mud that got on the wound and if they could get into his body. I can now make him calm down. Much better than I could before.

Me: What did you tell him?

Mia: I said now you go up to the club [at school] and you will get it cleaned. And that was it. You can now talk reason to him in a way you couldn't before.

Me: Do you think that you talk to him differently than you did before you came to the program?

Mia: No, I don't think so. He is better in accepting it. On that occasion he then remembered another time he had hurt himself much worse and how well everything went with the wound healing nicely.

Although Erik still felt the need to call his mother when he got hurt, he was able to accept what she told him and calm down instead of thinking of the worst case scenario, as he often did before treatment. Furthermore, he was able to apply his knowledge from previous experiences, in which everything went well, to the current situation, concluding that things would probably go similarly this time. In this way, he was able to apply tools he learned in treatment. Additionally, the mother did not overreact in the situation and thus did not signal to Erik that he was in a dangerous situation, as she had done in the past. 
A "Cool Kids" Cognitive-Behavioral Therapy Group for Youth with Anxiety Disorders:

Part 1, The Case of Erik

I. Lundkvist-Houndoumadi \& M. Thastum

Pragmatic Case Studies in Psychotherapy, http://pcsp.libraries.rutgers.edu

Volume 9, Module 2, Article 2, pp. 122-178, 06-26-13 [copyright by authors]

\section{Erik’s Evaluation of Treatment Outcome}

In the last session, when reviewing the situations he had feared when he came in to treatment, Erik said that his biggest fear, war, had subsided after he had heard about the existence of NATO. Erik seemed to have started obtaining more information about the things he feared, which resulted in him looking at things possibly more realistically.

At the 3-month follow-up I told Erik that his parents believed he had made impressive progress since the first time he came to the Anxiety Clinic. When I asked him what his impression was, he replied:

Erik: Yes, I also think I am managing much better now.

Me: What do you think has contributed to the fact that you are much better now?

Erik: Well, this thing here [the Cool Kids Program].

Me: Do you? Because I recall you thought that stepladders were stupid and you didn't really think detective thinking was any good either...

Erik: Yes, but I got the push that I needed.

Erik might not have been very motivated during the treatment, as he thought that the gradual stepladders were "stupid," did not want to acknowledge his anxiety, and experienced difficulty with cognitive restructuring. However, he seemed to think that the treatment helped him by giving him the push he needed to do the things he had avoided until then.

In the interview conducted 15 months after the end of therapy, Erik replied that he was afraid to walk alone in the night and to take the bus on his own, but he did not seem to worry excessively:

I can do many more things now. Earlier, I was... afraid of going outside to buy things for my mother. If she asks me to do that now, I just say: "Yes, sure, of course I can do it." So I think differently about things now. And I believe in myself more now than I did before I came here. I have also started playing the guitar and this [guitar playing] helps me a lot. I don't think of all the things I used to because I concentrate on playing and my head is filled up with it...Earlier I was someone the others overlooked in my class and they didn't care about me. Now I have actually gained a lot of respect in my class. Before I would do as they told me to. Then I pulled myself together to talk back to them and this has given me respect in my class.

As was apparent from the parents' interview, Erik had gotten more self-confident and proud of himself. He felt that he had gained respect in his class, which was supported by his mother's description of his newfound ability to speak up. Bullying, one of the maintaining factors of Erik's anxiety, had disappeared. Erik now had the energy to engage in an extracurricular activity instead of worrying. 
A "Cool Kids" Cognitive-Behavioral Therapy Group for Youth with Anxiety Disorders:

Part 1, The Case of Erik

I. Lundkvist-Houndoumadi \& M. Thastum

Pragmatic Case Studies in Psychotherapy, http://pcsp.libraries.rutgers.edu

Volume 9, Module 2, Article 2, pp. 122-178, 06-26-13 [copyright by authors]

\section{Evaluation of Treatment Program}

Erik and his parents completed the Service Evaluation Questionnaire (SEQ) after the end of treatment, and each individual reported feeling fully satisfied with the Cool Kids Program and the help it had provided them.

Interestingly, Ib responded to the question that asked if there was something he disliked about the program by saying: "Not all children (Erik) are good in the theoretical part of the program—stepladder, detective thinking. Maybe more practical exercises like the time at the shopping mall?”

Fifteen months after the end of treatment, the parents' scores on the quantitative part of the interview (see Table 1 for the measure) indicated that they were still very satisfied with the treatment overall.

This is clearly what has helped him the most. This is what he talks about, if he talks about something. He had also talked with a psychiatrist, but he has never talked about that...We also spent a lot of time alone in the parents' group and there it might have been good to give us some group exercises. We had a nice time together with the other parents, but I can imagine we were lucky and this might not always be the case.

When Erik was asked what he thought about the treatment program in general, he reported that the therapy had helped him immensely and he found the experience to be fun overall. He said:

I could from each time [sic] feel that it actually helped me. I sometimes did homework so that I could keep it up until the next time I came [to therapy]. It has helped me go on with my life.

When asked if he could remember anything from the program that was either fun or boring, he replied:

I remember the time at the shopping mall. I felt pressured a lot. I was supposed to buy a present for my mother in a shop...Something I liked was the play [role playing in social skills]. It was a lot of fun. It was a nice way of learning something. I generally learn more by doing things instead of sitting down with a piece of paper [the written exercises in therapy sessions]. More active things in therapy [like the role playing] would be a good idea.

Overall, the family was very happy about the therapy format, although both Ib and Erik believed more active tasks in the sessions, such as role playing or exposure exercises, made the biggest impression and were most helpful for Erik, possibly due to his cognitive difficulties.

\section{Discussion of Possible Mechanisms of Change}

\section{$\underline{\text { Developmental Considerations and Motivational Issues }}$}

The ultimate goal of CBT with anxious children is to allow children to gain a sense of mastery over their anxiety. However, as children often do not come to therapy of their own 
A "Cool Kids" Cognitive-Behavioral Therapy Group for Youth with Anxiety Disorders:

Part 1, The Case of Erik

I. Lundkvist-Houndoumadi \& M. Thastum

Pragmatic Case Studies in Psychotherapy, http://pcsp.libraries.rutgers.edu

Volume 9, Module 2, Article 2, pp. 122-178, 06-26-13 [copyright by authors]

volition, it can be argued that the first, and arguably most important, step toward a successful treatment is getting the child motivated and engaged in the therapy process. Erik was initially fairly unmotivated, talking about how he was tired of psychologists and psychiatrists. His initial lack of motivation might be partly explained by the difficulties he faced while doing cognitive restructuring during therapy.

Erik's lack of motivation may be also explained by the fact that his problems had been an issue of focus for so long that he was tired of being in the center of attention. This was confirmed at the interview conducted 15 months after the end of treatment, as the mother said:

One thing I thought was that it demanded too much, that Erik was so tired of it at periods that he didn't want to make an effort: "Oh no, now we have to go there again." But of course children can’t really see that this is something which helps them and Erik had already seen many psychologists and psychiatrists."

Furthermore, it bothered Erik that he was the eldest in the group therapy; according to his mother, "The only negative thing about the program for us was that Erik was in a group of children that were younger than him.” Erik thought that he was not taken seriously when the psychologist spoke to the children as if they were very young, and believed the reward system to be "childish.” He was at an age when it was important for him to be thought of as mature. This also becomes evident in his mother's description of how well he managed to go to the dentist, "Erik told me that the next time he will tell the dentist: 'You don't have to talk to me as if I am a child.” During therapy, Erik often preferred talking with the student-therapists in the group, rather than the other children. It is possible that Erik was aware that he could not do some of the things other kids of his age could, and this might have made him feel the need to emphasize that he was neither childish nor immature. When the psychologist altered the way he talked to him, explaining that Erik was not placed in a group with younger children on purpose, it ceased being a big problem. It is possible that he even started enjoying being the eldest in the group. Although we told him that it was not his responsibility, he often participated in the other children's games and tried keeping them quiet.

Erik's difficulty in admitting his anxiety problems may have been partly due to the fact that he felt pressured to demonstrate how much he could do so that he might show to the other children that he was older than them. For instance, when talking to one of the children Erik was overheard, saying that he would go wind-surfing with Peter:

Child: Are you not afraid?

Erik: No.

Child: And what if you fall in the water? Can you swim?

Erik: Well no, but I'll just learn it on my way out to the shore.

On the other hand, the fact that Erik was in a group with other children who also had various anxiety disorders, may have had a positive influence on Erik, as his anxieties were normalized and accepted. Through therapy, Erik's beliefs about himself changed as he started to compare himself with other children instead of comparing himself to how he was prior to therapy (a child with anxiety). When praised for his progress in therapy, he commented, "That's nothing. That's normal!” 
A "Cool Kids" Cognitive-Behavioral Therapy Group for Youth with Anxiety Disorders:

Part 1, The Case of Erik

I. Lundkvist-Houndoumadi \& M. Thastum

Pragmatic Case Studies in Psychotherapy, http://pcsp.libraries.rutgers.edu

Volume 9, Module 2, Article 2, pp. 122-178, 06-26-13 [copyright by authors]

\section{Cognitive Versus Behavioral Elements in Treatment}

Erik's anxiety in a number of situations can be related to cognitive distortions and can be explained through the theoretical model proposed by Muris and Field (2008). The model suggests that cognitive distortions influence the processing of threat-related information, which is thought to play a role in the maintenance of childhood anxiety. Erik's vulnerability and danger schema were overactive, which led him to attend to potentially threatening stimuli (e.g., a car stopping across him at the street) in the encoding stage of information processing. In the interpretation stage of the information processing, Erik understood situations as threatening (e.g., the people in the car wanted to kidnap him) and his memory bias made him think of the event in which some children had run after him, leading him to expect that this might happen again. This biased information processing readily elicited the feelings of fear and anxiety, thereby enhancing the occurrence of cognitive biases and further strengthening Erik's maladaptive vulnerability and danger schemas. This provides support for Kendall's (1985) cognitive theory and corroborates earlier findings (Kendall et al., 1992; Kendall \& PanichelliMindel, 1995) that anxious children tend to misperceive ambiguous situations as threatening.

CBT stresses that behaviors are regulated by appraisals of stimuli rather than the stimuli themselves (Bolton, 2005). This assumes that what is critical for problematic behavior and emotion is the regulation of the appraisals. In Erik's case this would mean that after we identified the maladaptive appraisals leading him to believe the world was dangerous (e.g., not wanting to go to the shopping mall alone because he would be kidnapped), we should have addressed these appraisals in therapy so that the maladaptive reactions could be altered. Nevertheless, Erik found cognitive restructuring difficult at the time of therapy. Although similar cognitive distortions are found in both children and adults, interventions with children should consider their level of cognitive development in addition to the family and wider systemic factors.

Studies indicate that older children are often more responsive to cognitive approaches than younger children (O’Connor \& Creswell, 2005). Although Erik was older than the other children, his cognitive difficulties may have contributed to him not progressing with the cognitive exercises (e.g., cognitive restructuring). Erik's cognitive delay and difficulties with auditory short-term memory might explain why he had problems following instructions on how to do cognitive restructuring. Short-term memory is important when learning new things; if it is impaired, this has consequences for the storage of information in the long-term memory. Furthermore, his below average attention span and poor processing speed made it hard for Erik to keep up with the rate of the group and he quickly became tired. Additionally, when combined with socio-emotional aspects of Erik's functioning, his cognitive difficulties indirectly fed into his anxiety. Erik's difficulty verbally asserting himself and providing quick answers when confronted also played a role in him being bullied in school. In conjunction with being behind others academically, his experience of bullying may have contributed to Erik's low self-esteem and the maintenance of his anxiety, as he believed himself incapable of managing on his own.

In contrast to the cognitive component of CBT, Erik made impressive progress through the behavioral component of therapy (exposures). Empirical evidence indicates that the exposure portion of treatment is an important contributor to treatment success when working with anxious children (Kendall et al., 1997), and Erik's case supports this. Evidence indicates that exposures 
A "Cool Kids" Cognitive-Behavioral Therapy Group for Youth with Anxiety Disorders:

Part 1, The Case of Erik

I. Lundkvist-Houndoumadi \& M. Thastum

Pragmatic Case Studies in Psychotherapy, http://pcsp.libraries.rutgers.edu

Volume 9, Module 2, Article 2, pp. 122-178, 06-26-13 [copyright by authors]

effectively reduce fears when clients successfully learn and consolidate new, context-dependent information that is incompatible with their existing representations of threat, based on memories and expectations of feared consequences. Such learning happens through an NMDA-mediated neurobiological network involving the prefrontal cortex, amygdala, and hippocampus (Moscovitch, Antony \& Swinson, 2008).

Through exposures, Erik's cognitive distortions related to his over-active schemas about danger and vulnerability were challenged and alternative thoughts emerged, supported by others' positive feedback. This was the case when Erik came out of the store after buying food, smiling and saying that the shop assistant was very sweet. Through exposures, alternative thoughts emerged that painted the world as less dangerous and Erik as able to manage more situations than previously thought. The importance of exposures is also underscored by Erik's comment at the 3-month follow-up, when he said that therapy had helped him because it gave him "the push" he needed.

During the course of therapy, it was our impression that Erik experienced problems in the cognitive components of therapy (detective thinking), while the exposures (stepladders) had a greater impact on the therapeutic outcome. Thus it was surprising when, in the interview 15 months after the end of therapy, Erik was asked which component of therapy helped him the most and responded:

Erik: Detective thinking is what has helped me through most of my life. When I have been in a situation, as for example, alone outside, taking a bus, then I have used it and I have thought: "What could happen? What is the worst that could happen? Why?" And things like that...And this has helped me a lot. Then I am not at all afraid afterwards. Then I totally relax. I usually remember to use it myself and my parents remind me of it sometimes.

Me: What about the stepladders?

Erik: No, I don’t really use it. I think I am about to be free of all my problems. I can’t actually remember the last time I had an anxiety problem. It is a really long time ago.

The above exchange highlights a significant change compared to Erik's statements during therapy. Stepladders were then thought to be the most significant component of therapy that contributed to the favorable therapy outcome. Fifteen months later, Erik was not overtly using this method and he was not experiencing problematic anxiety issues. Instead, he claimed to be using detective thinking, a fact that may reflect his advancing cognitive maturation. Due to Erik's difficulties with cognitive restructuring (detective thinking), we focused more on doing exposures with him in treatment. However, the mother learned to practice detective thinking with him and gradually introduced it to him as he matured, so that Erik was able to integrate it into his way of thinking.

In Erik's case, his mother played an important role by influencing his beliefs about the world as dangerous and Erik as needing help to handle certain situations. Mia also expected bad things to happen; her first reaction when Erik would go to her room was: "What is wrong?" 
A "Cool Kids" Cognitive-Behavioral Therapy Group for Youth with Anxiety Disorders:

Part 1, The Case of Erik

I. Lundkvist-Houndoumadi \& M. Thastum

Pragmatic Case Studies in Psychotherapy, http://pcsp.libraries.rutgers.edu

Volume 9, Module 2, Article 2, pp. 122-178, 06-26-13 [copyright by authors]

At the 15-month follow-up, Erik reported that his parents behaved differently toward him when he got afraid:

They help me more [now, compared to before treatment]. In the beginning they ignored it [anxiety]. It took some time before they understood that something was wrong. Now when I come to them they listen and they help me. They tell me all kinds of things: What could happen if... What is the likelihood that this happens... And that is actually something that really helps me a lot.

Erik's description indicates that his parents used detective thinking with him when he got anxious. This may further explain why he considered detective thinking to be the most helpful component 15 months after the end of treatment.

As mentioned, CBT stresses that behaviors are regulated by appraisals of stimuli. Interventions targeted at children with anxiety should also consider the role of the family, which influences the generation and/or maintenance of the anxiety disorder (Stallard, 2002). This is beautifully illustrated by the way Mia's behavior toward Erik changed after therapy. During therapy Mia saw how Erik could do more and more things on his own: "Now I have also seen how much he manages on his own and I trust him.” This influenced her appraisal of Erik's need for support, which in turn influenced the way she behaved towards him. Gradually, a new narrative emerged about Erik, who changed from being an anxious child to a courageous child. The way her expectations of what Erik could manage were altered during therapy was also mentioned in the 15-month follow-up interview:

I think my expectations have changed. He can do many more things than before he started in therapy. And our expectations [for what Erik would manage] were probably not so high before we started therapy. Both we and he have gotten some tools in order to tackle the anxiety. I have also thought a lot about my anxiety and that I shouldn't transfer it to him, and I have generally gotten a better understanding of anxiety: what it does to children, what parents should say and what they shouldn't. I learned how I should tackle my own anxiety, and how I shouldn't overprotect Erik. I don't do that [overprotect] anymore.

The importance of including parents in the treatment became apparent; in addition to changing their appraisal of their child's situation, the parents acquire skills for coping with their own anxiety and managing their child's worries. All these factors, which may contribute to favorable long-term effects in therapy, will be considered in more detail in the following section.

\section{Family Influence in Therapy Outcome}

In accordance to Rapee’s model (2001, seen in Figure 1), Erik’s case illustrates the bidirectional nature of influences between the child and the environment, as well as the role of parental anxiety. Erik’s mother, Mia, had mentioned how she was concerned that it was her fault that Erik had anxiety. We talked with her about how multiple factors may lead to the development of anxiety and that there was no point in looking at the past when she should focus on how she could best help Erik in the future. We explained to her how the way she reacted to Erik was related to the way he behaved, mentioning that studies have shown that biologically unrelated mothers were also more involved when interacting with anxious children (Hudson, 
A "Cool Kids" Cognitive-Behavioral Therapy Group for Youth with Anxiety Disorders:

Part 1, The Case of Erik

I. Lundkvist-Houndoumadi \& M. Thastum

Pragmatic Case Studies in Psychotherapy, http://pcsp.libraries.rutgers.edu

Volume 9, Module 2, Article 2, pp. 122-178, 06-26-13 [copyright by authors]

Doyle \& Gar, 2009). By pointing out that children who are anxious may evoke a certain controlling response from others, we tried to normalize the way she had reacted towards Erik.

Mia's anxiety interfered with her ability to teach Erik coping skills. She also modeled anxious behaviors, presenting situations as dangerous, such as the time she told him that he might have to wait alone in the theme park. This may have contributed to Erik's avoidance of situations in the past and maintained his anxiety. However, Mia seemed to find it difficult to understand how things that did not scare her could be difficult for Erik. Thus, she was occasionally unsupportive and even negative toward Erik, as when she could not encourage Erik to do the exposures in the shopping mall, dismissing his social anxiety and saying that his fear was stupid. After pointing out to her how her behavior could impact Erik and his ability to do things that were difficult for him, she became motivated to try and manage her own anxiety and alter her behavior. She gave multiple examples of how she might have been overprotective in therapy, and ultimately realized she should change these behaviors. Through therapy, Mia made tremendous progress. Although she still worried about Erik at times, she talked about it with her husband and managed it in a way that did not influence Erik negatively. This is in agreement with earlier reported findings that indicate that a family-based treatment is particularly effective for children whose parents have an anxiety disorder (Cobham, Dads, \& Spence, 1998).

At the 15-month interview Mia explained how her behavior toward Erik had changed in situations in which he got anxious:

After therapy one should remind oneself and think not to go back to the same patterns. If you are a bit stressed... It doesn't take any time to say to the child: "Stop what you are doing [being worried about something]!" or "I’ll do it for you." But you should instead try and help the child the right way; have the time to talk with him. We have used that thing with saying: "What would the detective do? Try and do some detective thinking on it." We have changed in the way that we have gotten some tools here on how we should talk with Erik. I also think I use it [posing detective thinking questions] on myself ...that more logical way of thinking.

Mia's engagement in therapy was evident throughout therapy and had a long-term effect on the way she interacted with Erik. Her engagement was obvious from the start of therapy, as she provided examples of situations that Erik feared so that we were able to talk to Erik about his anxieties. However, after Erik had made progress, she became less involved in encouraging him to work on the planned stepladders. In the 15-month follow-up interview she commented that the stepladders demanded a lot of time; this may partly explain her lack of encouragement of Erik in the exposure exercises. It is also possible that when she became aware of her overprotective behavior, Mia was afraid of getting over-involved and wanted to show that she trusted him. At the same time, one should not underestimate the possible adverse effects of the mother being fired from her work during that time. Nevertheless, Erik could have profited from parental assistance with the exercises in between sessions, as he often experienced difficulties in working in an organized manner.

At the 15-month follow-up interview the parents seemed reluctant to push Erik to make further progress. When asked whether they had considered doing a stepladder independently, they replied: 
A "Cool Kids" Cognitive-Behavioral Therapy Group for Youth with Anxiety Disorders:

Part 1, The Case of Erik

I. Lundkvist-Houndoumadi \& M. Thastum

Pragmatic Case Studies in Psychotherapy, http://pcsp.libraries.rutgers.edu

Volume 9, Module 2, Article 2, pp. 122-178, 06-26-13 [copyright by authors]

Mother: Yes, then [when Erik no longer can stay at school until the father gets free from work] we could try and do a stepladder. We haven't done it until now. Sometimes it's just more convenient just to pick him up. Ib gets free from work at that time. But if Erik had to do it [take the bus alone], I think he would be able to. He just has to try it a couple of times.

Father: Yes, he should be pushed a bit.

Mother: In the summer he was with one of his friends and asked me if I would drive them to the city and when I said I couldn't, they did it on their own. When he is with others, he might get a bit anxious, but he manages.

It is apparent that parental motivation for the child to change affects progress. Erik's parents showed signs of doubt that they could face the challenges ahead of them, and needed more support in their parenting. During the last therapy sessions, Mia kept asking if there was an option of adding more sessions, because they would be on their own again after the conclusion of the program. We tried to emphasize how much progress they had made as a family and asked them if there was something they specifically needed our help with in planning future work. Mia did not ask us about anything and the family never contacted us for additional sessions, suggesting that the family had gotten some tools in order to be able to manage on their own. Nevertheless, at the 15-month follow-up interview, Mia appeared to need further support, mentioning that Erik's brother was now experiencing anxiety problems and had been placed on a waiting list at the Children's Anxiety Clinic. When asked why she did not use some of the principles she had learned in Erik's treatment, she said:

He has some totally different problems and we don't really know what he is afraid of...But it has been hard for me to have suddenly two children with anxiety. I think if we come here, it will also keep me going so I don't get tired of it.

Mia mentioned that she felt supported by her husband during the course of the treatment. Ib became more involved in Erik's treatment after he was informed about how he could be a positive role model. It also seemed important for Erik to show his dad that he could do things. For example, he was very proud of himself when he touched a snake his father did not dare touch. Erik's motivation to make his dad proud might have also contributed to the father trying to alter his behavior.

However, at the 15-month interview the father claimed that he had not changed his behavior towards Erik due to the program. It is possible that Ib thought that he did not need to alter his behavior because he did not have anxiety. Nonetheless, it is our impression that the father had a very positive influence on the treatment of Erik's anxiety. Future studies may benefit from incorporating fathers into therapy and further exploring the ways they may contribute to favorable outcomes in the treatment of childhood anxiety. There is already some evidence that various types of developmental psychopathology reveal better long-term effects when fathers are included in treatment (e.g. Bagner \& Eyberg, 2003).

Finally, in addition to the family, another aspect of Erik's environment is the neighborhood in which he lived. That neighborhood is reported to have an elevated crime rate, possibly contributing to him hearing about crimes and thinking of people as dangerous gang 
A "Cool Kids" Cognitive-Behavioral Therapy Group for Youth with Anxiety Disorders:

Part 1, The Case of Erik

I. Lundkvist-Houndoumadi \& M. Thastum

Pragmatic Case Studies in Psychotherapy, http://pcsp.libraries.rutgers.edu

Volume 9, Module 2, Article 2, pp. 122-178, 06-26-13 [copyright by authors]

members who kidnap children. When interviewed 15 months after treatment, the family had moved to a smaller city, a move that may have contributed to his progress.

\section{Conclusion}

Based on all the data and our clinical experience in the case, we believe the positive treatment outcome obtained by Erik can be mainly attributed to the following factors. First, consideration of the bi-directionality of influences and the contextual maintaining factors (especially as they were expressed through the mother's anxiety) was instrumental in setting up the case conceptualization and individualized treatment plan based on the Cool Kids Program.

Second, during the course of treatment, the importance of including parents was underscored, as their engagement supported Erik when he was faced with anxiety provoking situations by reminding him of the coping skills he had already acquired. The parents' engagement also allowed Erik's mother to become more aware of how her worries helped maintain Erik's anxiety and, ultimately, acquire skills to handle it in a way that didn't negatively affect her son. Thirdly, monitoring of the therapy process revealed the necessity of accommodating to Erik's specific cognitive abilities. Although cognitive distortions were present, cognitive interventions proved to be difficult due to his learning difficulties. Erik's cognitions were initially successfully challenged through gradual exposures. Eventually, with the help of his parents and his advancing cognitive maturation, he was able to integrate cognitive restructuring into his thinking.

The maintenance of the overall positive therapeutic outcome as seen in quantitative and qualitative data at 3 months and 15 months post-treatment follow-up may be attributed to the fact that parents were taught skills that supported the child in anxiety-provoking situations and also altered their expectations and behaviors towards the child, learning to function as positive role models.

\section{REFERENCES}

Albano, A.M., Causey, D. \& Carter, B. (2001). Fear and anxiety in children. In: C.E. Walker \& M.C. Roberts (Eds), Handbook of clinical child psychology (3rd ed., pp. 291-316). New York: John Wiley \& Sons.

Albano, A.M., Chorpita, B.F. \& Barlow, D.H. (1996). Anxiety disorders. In: E.J. Mash \& R.A. Barkley (Eds), Child psychopathology (pp. 196-241). New York: Guilford Press.

Albano, A. M., \& Silverman, W. K. (1996). Anxiety Disorders Interview Schedule for DSM - IV. Child version. Oxford: Oxford University Press.

Allen, J. L., \& Rapee, R.M. (2005). Anxiety disorders. In P.J.Graham (Ed.), Cognitive behaviour therapy for children and adolescents (2nd ed., pp. 300-319). Cambridge University Press.

American Psychiatric Association: Diagnostic and statistical manual of mental disorders, fourth edition, text revision. Washington, DC, American Psychiatric Association, 2000.

Bagner, D. M., \& Eyberg, S. M. (2003). Father involvement in parent training: When does it matter. Journal of Clinical Child and Adolescent Psychology, 32, 599-605.

Barlow, D.H. (2002). Anxiety and its disorders, 2nd edn. New York: Guilford Press.

Barrett, P.M. (1998). Evaluation of cognitive-behavioral group treatments for childhood anxiety 
A "Cool Kids" Cognitive-Behavioral Therapy Group for Youth with Anxiety Disorders:

Part 1, The Case of Erik

I. Lundkvist-Houndoumadi \& M. Thastum

Pragmatic Case Studies in Psychotherapy, http://pcsp.libraries.rutgers.edu

Volume 9, Module 2, Article 2, pp. 122-178, 06-26-13 [copyright by authors]

disorders. Journal of Clinical Child Psychology, 27(4), 459-468.

Barrett, P. M., Dadds, M. R., \& Rapee, R. M. (1996). Family treatment of childhood anxiety: A controlled trial. Journal of Consulting and Clinical Psychology, 64(2), 333-342.

Beck, J. S., Beck, A. T., \& Jolly, J. (2001). Beck Youth Inventories ${ }^{\mathrm{TM}}$ of Emotional and Social Impairment. The Psychological Corporation.

Bögels, S. M., \& Brechman-Toussaint, M. (2006). Family issues in child anxiety: Attachment, family functioning, parental rearing and beliefs. Clinical Psychology Review, 26(7), 834856.

Bögels, S., \& Phares, V. (2008). Fathers' role in the etiology, prevention and treatment of child anxiety: A review and new model. Clinical Psychology Review, 28(4), 539-558.

Bolton, D. (2005). Cognitive Behaviour therapy for children and adolescents: some theoretical and developmental issues. In P.J. Graham (Ed.), Cognitive Behaviour Therapy for Children and Families (2 ed., pp. 9-24). Cambridge University Press.

Carr, A. (1999). The handbook of child and adolescent clinical psychology: A Contextual Approach. New York: Routledge.

Chorpita, B., Albano, A.,\&Barlow,D. (1996). Cognitive processing in children: Relation to anxiety and family influences. Journal of Clinical Child Psychology, 25, 170-176.

Cobham, V.E., Dadds, M.R. \& Spence, S.H. (1998). The role of parental anxiety in the treatment of childhood anxiety. Journal of Consulting and Clinical Psychology, 66, 893-905.

Cohen, J. (1988). Statistical power analysis for the behavioral sciences ( $2^{\text {nd }}$ ed.). New Jersey: Erlbaum.

Essau, C.A., Conradt, J., Petermann, F. (2000). Frequency, comorbidity, and psychosocial impairment of anxiety disorders in German adolescents. Journal of Anxiety Disorders, 14, 263-279. In E.J. Mash \& D.A. Wolfe, D.A. (2008). Abnormal child psychology. 4th Ed. Wadsworth Cengage Learning, Canada.

Fennel, M. (1989). Depression. In K. Hawton, K., P.M. Salkovskis, J. Kirk, \& D.M. Clark (Eds.), Cognitive behaviour therapy for psychiatric problems. A practical guide. Oxford: Oxford Medical Publications.

Gar, N.S., Hudson, J.L., \& Rapee, R.M. (2005). Family factors and the development of anxiety disorders. In J. L. Hudson, \& R. M. Rapee (Eds.), Psychopathology and the family. (pp. 125-145). New York, NY, US: Elsevier Science.

Ginsburg, G.S., \& Schlossberg, M.C. (2002). Family-based treatment of childhood anxiety disorders. International Review of Psychiatry, 14(2), 143-154.

Goodman, R. (1997). The Strengths and Difficulties Questionnaire: A research note. Journal of Child Psychology and Psychiatry, 38, 581-586.

Goodman, R., \& Scott, S. (1999) Comparing the Strengths and Difficulties Questionnaire and the Child Behavior Checklist: Is small beautiful? Journal of Abnormal Child Psychology, 27, 17-24.

Hougaard, E., Madsen, S. S., Hansen, L. M., Jensen, M., Katborg, G. S., Morsaa, L. et al. (2008). A novel group therapeutic format in cognitive behavioral treatment for clients with social phobia in a training setting: A case study of one treatment group with nine clients. Pragmatic Case Studies in Psychotherapy [Online],Vol. 4(4), Article 1, 1-52. Available: http://hdl.rutgers.edu/1782.1/pcsp_journal.

Hudson, J.L., Doyle, A., \& Gar, N.S. (2009). Child and maternal influence on parenting behaviour in clinically anxious children. Journal of Clinical Child and Adolescent 
A "Cool Kids" Cognitive-Behavioral Therapy Group for Youth with Anxiety Disorders:

Part 1, The Case of Erik

I. Lundkvist-Houndoumadi \& M. Thastum

Pragmatic Case Studies in Psychotherapy, http://pcsp. libraries.rutgers.edu

Volume 9, Module 2, Article 2, pp. 122-178, 06-26-13 [copyright by authors]

Psychology, 38(2), pp. 256-262.

Hudson, J. L., \& Rapee, R. M. (2009). Familial and social environments in the etiology and maintenance of anxiety disorders. In M. M. Antony \& M. B. Stein (Eds.), Oxford handbook of anxiety and related disorders. (pp. 173-189). New York, NY, US: Oxford University Press.

Jacobson, N.S. \& Truax, P. (1991). Clinical significance: A Statistical approach to defining meaningful change in psychotherapy research. Journal of Consulting and Clinical Psychology, 59 (1), 12-19.

Kazdin, A.E. \& Weisz, J.R. (1998). Identifying and developing empirically supported child and adolescent treatments. Journal of Consulting and Clinical Psychology, 66, 19-36.

Kendall, P.C. (1985). Toward a cognitive-behavioral model of child psychopathology and a critique of related interventions. Journal of Abnormal Child Psychology, 13, 357-372.

Kendall, P.C. (Ed.) (2000). Child and adolescent therapy: Cognitive-behavioral procedures (2nd ed.). New York: Guilford Press.

Kendall, P. C., Chansky, T., Kane, M., Kim, R., Kortlander, E., Ronan, K., Sessa, F.M., \& Siqueland, L. (1992). Anxiety disorders in youth: Cognitive-behavioral interventions. Needham Heights, MA: Allyn \& Bacon.

Kendall, P.C., Flannery-Schroeder, E., Panichelli-Mindel, S.M., Southam-Gerow, M., Henin, A. \& Warman, A. (1997). Therapy for youths with anxiety disorders: A second randomized clinical trial. Journal of Consulting and Clinical Psychology, 65, 366-380.

Kendall, P.C., \& Panichelli-Mindell, S.M. (1995). Cognitive behavioral treatments. Journal of Abnormal Child Psychology, 23, 107-124.

Lazar, A., Sagi, A. \& Fraser, M. W. (1991). Involving fathers in social services. Children and Youth Services Review, 13, 287-300

Lundkvist-Houndoumadi, I., \& Thastum, M. (2010). The case study of a child with anxiety disorders: The role of parental inclusion and the child's cognitive developmental level in applying the Cool Kids program at a university clinic. Unpublished manuscript, The Anxiety Disorder Clinic for Children and Adolescents, Department of Psychology, Aarhus University, Denmark.

Lundkvist-Houndoumadi, I., \& Thastum, M. (2013). A "Cool Kids" cognitive-behavioral therapy group for youth with anxiety disorders: Part 2, Analysis of the process and outcome of responders versus nonresponders. Pragmatic Case Studies in Psychotherapy, http://pcsp.libraries.rutgers.edu. Vol 9 (2), Article 4, pp. 179-274.

Lyneham, H.J., Abbott, M.J., Wignall, A. \& Rapee, R.M. (2003). The Cool Kids ${ }^{\circledR}$ Program: Children's workbook. MUARU: Macquarie University, Sydney.

Lyneham, H.J., Abbott. M.J., Rapee, R.M., Tolin, D.F., Carlson, S.E., \& Hudson, J.L. (in preparation). Psychometric properties of the Child Anxiety Life Interference Scale (CALIS). Retrieved from: http://www.psy.mq.edu.au/CEH/CALIS.html (CALIS Scoring [pdffile[)

Mendlowitz, S.L., Manassis, K., Bradley, S., Scapillato, D., Miezitis, S., \& Shaw, B. (1999). Cognitive-behavioral group treatments in childhood anxiety disorders: The role of parental involvement. Journal of the American Academy of Child and Adolescent Psychiatry, 38, 1223-1229.

Moscovitch, D.A., Antony, M.M., \& Swinson, R.P. (2008). Exposure-based treatments for anxiety disorders: Theory and process. In: M.M. Antony \& M.B. Stein (eds.), Oxford 
A "Cool Kids" Cognitive-Behavioral Therapy Group for Youth with Anxiety Disorders:

Part 1, The Case of Erik

I. Lundkvist-Houndoumadi \& M. Thastum

Pragmatic Case Studies in Psychotherapy, http://pcsp.libraries.rutgers.edu

Volume 9, Module 2, Article 2, pp. 122-178, 06-26-13 [copyright by authors]

handbook of anxiety and related disorders (pp. 461-475). Oxford: Oxford University Press.

Muris, P. \& Field, A. P. (2008). Distorted cognition and pathological anxiety in children and adolescents. Cognition \& Emotion, 22, 395-421.

Muris, P., Steerneman, P., Merckelbach H., \& Meesters, C. (1996). The role of parental fearfulness and modeling in children's fear, Behaviour Research and Therapy 34, 265268.

O’ Connor, T., \& Creswell, C. (2005). Cognitive behaviour therapy in developmental perspective. In P.J. Graham (Ed.), Cognitive Behaviour Therapy for Children and Families (2nd ed., pp. 25-47). Cambridge University Press.

Ollendick, T., King, N., \& Yule, W. (1994).International handbook of phobic and anxiety disorders in children and adolescents. New York: Plenum.

Pine, D.S., Cohen, P., Gurley, D., Brook, J. \& Ma, Y. (1998). The risk for early-adulthood anxiety and depressive disorders in adolescents with anxiety and depressive disorders. Archives of General Psychiatry, 55, 56-64.

Rapee, R.M. (2001). The development of generalized anxiety. In M. W. Vasey and M. R. Dadds (eds.), The developmental psychopathology of anxiety. Oxford: Oxford University Press, pp. 481-503.

Rapee, R.M., Lyneham, H.J., Schniering, C.A., Wuthrich, V. Abbott, M.A., Hudson J.L., \& Wignall, A., (2006). The Cool Kids ${ }^{\circledR}$ Child and Adolescent Anxiety Program Therapist Manual. Centre for Emotional Health, Macquarie University: Sydney.

Rapee, Wignall, Hudson \& Schniering (2000). Treating anxious children and adolescents: An evidence-based approach. New Harbinger Publications.

Reynolds, S., Wilson, C., Austin, J., \& Hooper, L. (2012). Effects of psychotherapy for anxiety in children and adolescents: A meta-analytic review. Clinical Psychology Review, 32, 251262.

Shortt, A., Barrett, P.M. \& Fox, T. (2001). Evaluating the FRIENDS program: A cognitivebehavioral group treatment for anxious children and their parents. Journal of Clinical Child Psychology, 30(4), 525-535.

Silverman, W.K., Kurtines, W.M., Ginsburg, G.S., Weems, C.F., Lumpkin, P.W. \& Carmichael, D.H. (1999). Treating anxiety disorders in children with group cognitive behavior therapy: a randomized clinical trial. Journal of Consulting and Clinical Psychology, 67, 995-1003.

Spence, S.H. (1998). A measure of anxiety symptoms among children. Behaviour Research and Therapy, 36(5), 545-566.

Spence, S.H., Donovan, C., \& Brechman-Toussaint, M. (2000). The treatment of childhood social phobia: the effectiveness of a social skills training-based, cognitive-behavioral intervention, with and without parental involvement. Journal of Child Psychology and Psychiatry and Allied Disciplines, 41(6), 713-726.

Stallard, P. (2002). Cognitive behaviour therapy with children and young people: A selective review of key issues. Behavioral and Cognitive Psychotherapy, 30:297-309.

Thastum, M., Ravn, K., Sommer, S., \& Trillingsgaard, A. (2009). Reliability, validity and normative data for the Danish Beck Youth Inventories. Scandinavian Journal of Psychology, 50, 47-54. 
A "Cool Kids" Cognitive-Behavioral Therapy Group for Youth with Anxiety Disorders:

Part 1, The Case of Erik

I. Lundkvist-Houndoumadi \& M. Thastum

Pragmatic Case Studies in Psychotherapy, http://pcsp.libraries.rutgers.edu

Volume 9, Module 2, Article 2, pp. 122-178, 06-26-13 [copyright by authors]

Wood, J. J., McLeod, B. D., Sigman, M., Chu, B. C., \& Hwang, W. (2003). Parenting and childhood anxiety: Theory, empirical findings, and future directions. Journal of Child Psychology and Psychiatry, 44(1), 134-151.

Wood, J.J, Piacentini, J.C., Bergman, R.L., McCracken, J., \& Barrios, V. (2002). Concurrent validity of the anxiety disorders section of the Anxiety Disorders Interview Schedule for DSM-IV: Child and Parent Versions. Journal of Clinical Child Adolescent Psychology, 31, 335-342. 
A "Cool Kids" Cognitive-Behavioral Therapy Group for Youth with Anxiety Disorders:

Part 1, The Case of Erik

I. Lundkvist-Houndoumadi \& M. Thastum

Pragmatic Case Studies in Psychotherapy, http://pcsp.libraries.rutgers.edu

Volume 9, Module 2, Article 2, pp. 122-178, 06-26-13 [copyright by authors]

\section{Table 1. Measures}

Anxiety Disorders Interview Schedule for DSM-IV, Child and Parent Versions (ADIS-C/P): The ADIS-C/P (Albano \& Silverman, 1996) is a semi-structured interview schedule of childhood DSM-IV disorders with favorable psychometric properties (Wood, Piacentini, Bergman, McCracken \& Barrios, 2002). The ADIS-C/P is developed by Albano and Silverman on a DSM-IV version (1996), originally as a modification of Anxiety Disorder Interview Schedule (ADIS) for adults. The interview exists in a parent-version (ADIS-P) and a version for children and youths aged 7-18 (ADIS-C). ADIS-C/P is administered by independent evaluators and yields diagnostic severity scores on the 0-8 clinical rating scale (CRS; $0=$ not at all, $4=$ some, $8=$ very, very much) for each anxiety disorder. Both parents and children are interviewed, and symptom reports from each are combined in making severity ratings.

Strengths and Difficulties Questionnaire (SDQ): The SDQ (Goodman, R. \& Scott, S., 1999) is a brief behavioral screening questionnaire for 3-16 year olds. The version used included 25 items on psychological attributes: All versions of the SDQ ask about 25 attributes, some positive and others negative. These 25 items are divided across 5 scales with 5 items each: 1) emotional symptoms 2) conduct problems 3) hyperactivity/inattention 4) peer relationship problems - that are added together to generate a total difficulties score and 5) prosocial behavior. The same 25 items are included in questionnaires for completion by the parents of 4-16 year olds (Goodman, 1997).

Beck Youth Inventories of Emotional and Social Impairment (BYI): The BYI (Beck, Beck \& Jolly, 2001) consists of five self-report scales; Self Concept (BSCI), Anxiety (BAI), Depression (BDI), Anger (BANI) and Disruptive Behavior (BDBI). Each inventory contains 20 statements written at a second grade level. The children are asked to indicate the extent to which they think that a sentence characterizes them best on a four point scale. The BYI therefore addresses also co-morbidity of disorders of negative affect (Thastum, Ravn, Sommer \& Trillingsgaard, 2009).

Spence Children's Anxiety Scale (SCAS): SCAS (Spence, 1998) is a 44-item scale assessing anxiety symptoms. Six subscales, corresponding to the anxiety disorders listed in the Diagnostic and Statistical Manual of Mental Disorders (American Psychiatric Association, 2000), are calculated from the anxiety items and a Total Anxiety score is obtained by summing ratings on all subscales. Participants rate each symptom on a 4-point scale corresponding to the frequency with which they experience each symptom, and higher scores reflect a greater number of anxiety symptoms.

Children's Anxiety Life Inference Scale (CALIS): CALIS (Lyneham et al., in preparation) is designed to assess life interference attributed to fears and worries from the child and parent perspectives. The measure targets interference in the child's life and also in the parents'/family's life. The CALIS is designed for children aged approximately 6 to 12 years of age.

15-month follow-up instruments (constructed by the first author): Parent version: A 5-point Likert type questionnaire addressed the following topics: Overall perception of the presence of anxiety $(\mathrm{Q} 1,2)$, perceived changes with respect to expectations and behavior towards the child that could be attributed to the treatment $(\mathrm{Q}$ $3,4,5,6,7)$, retrospective report of parental engagement in therapeutic components (Q 10), evaluation of each component $(Q 9,11)$, and overall evaluation of treatment program $(Q 8,12,13)$. After the completion of the questionnaire a semi-structured interview based on the topics of the questionnaire was carried out, in order to gain a better understanding of the processes which were related to therapeutic effect and maintenance of therapeutic gains.

Child version: A semi structured interview was based primarily on a questionnaire that helped the child assess the therapy in general, each of the different components and possible changes in parental attitudes and behavior.

Clinical Global Impression- Improvement of Anxiety (CGI-I). This instrument (Hougaard et al., 2008) is described in Table 2. 
A "Cool Kids" Cognitive-Behavioral Therapy Group for Youth with Anxiety Disorders:

Part 1, The Case of Erik

I. Lundkvist-Houndoumadi \& M. Thastum

Pragmatic Case Studies in Psychotherapy, http://pcsp. libraries.rutgers.edu

Volume 9, Module 2, Article 2, pp. 122-178, 06-26-13 [copyright by authors]

Table 2. Clinical Global Impression-Improvement of Anxiety (CGI-I)

This is a single rating of the child's condition post-treatment in comparison to their condition prior to the initiation of treatment based on behaviors, symptoms and functioning in all aspects of the child's life ( home, school, etc.) based on both parent and child report. Its background can be found in Hougaard et al. (2008).

\begin{tabular}{|l|l|}
\hline $\begin{array}{l}\text { CGI-I } \\
\text { rating }\end{array}$ & Description \\
\hline 1 & $\begin{array}{l}\text { Very much improved, good functioning (no diagnoses met), } \\
\text { minimal/subclinical symptoms, substantial change }\end{array}$ \\
\hline 2 & $\begin{array}{l}\text { Much improved, notably better, significant reduction of symptoms, though } \\
\text { some remain, increased functioning. } \\
\text { May retain diagnoses but reduction }>=2 \text { CSR points }\end{array}$ \\
\hline 3 & $\begin{array}{l}\text { Minimally improved, little or no clinically meaningful reduction of } \\
\text { symptoms, little change in clinical status and functional capacity }\end{array}$ \\
\hline 5 & $\begin{array}{l}\text { No change, symptoms unchanged } \\
\text { capacity }\end{array}$ \\
\hline 6 & Much worse, increase in symptoms and diminished functioning \\
\hline 7 & Very much worse, severe exacerbation of symptoms and loss of functioning \\
\hline
\end{tabular}

In case of inconsistencies across raters/ diagnoses reports:

- Where some CSRs have increased and others have decreased, take account of the CSR for primary diagnosis (carries more weight) in deciding if on balance there is a global improvement or not; however the extent of improvement/decline rated will be influenced by change in other diagnostic categories.

- Where parent and child give consistent reports on diagnoses weigh these more heavily when making a judgement

- Take account of child age when weighing utility of child ratings in decision making (i.e. more weight with increasing child age)

Note that this is not a linear scale, e.g., if a child had a fairly minor problem at the start, he or she might make a complete recovery and score 1 , in comparison to a child with a very severe problem who might experience a bigger absolute change but still retain some significant problems and score 2. 
A "Cool Kids" Cognitive-Behavioral Therapy Group for Youth with Anxiety Disorders:

\section{Table 3. E-Mail from Erik’s Parents at Pre-Treatment}

As agreed on the phone, we hereby send you a bit about our son Erik and his anxiety.

Erik can to a limited extent be home alone, but only if he knows where we are and for how long we are gone, e.g., when we go for shopping. He can be at home for a whole day with his little brother without us being there, but only when he is with his brother.

He has a phobia with washing hands and removing bacteria. He washes his hands often and he also demands we wash our hands after having touched for example detergents or before cooking. Erik has an unnatural approach to what is toxic and often wonders whether different things are toxic, which gives him an anxiety related to touching things he does not know.

Erik cannot transport himself from the leisure club to the sports hall $=500-600$ meters. We cannot send him out on an errand to buy milk, soft drinks, to the butcher or other places. He comes up with excuses in order to avoid these situations. He is approaching an age where it is embarrassing for him, when he is with friends and family, that his anxiety stops him from doing things.

He has been to consultations with a child psychiatrist over a longer period where the psychiatrist has followed Erik's anxiety and appealed to his common sense and logical thinking every time he came with examples of how his anxiety stopped him from completing the tasks he was given at the last meeting. Last consultation with the psychiatrist is now in March, and then will Erik be left to us and himself.

It is hard to come up with clarifications via email and we hope to get the opportunity to come with more examples and explanations of Erik’s disorder, which is a big handicap for him in his everyday life. 
A "Cool Kids" Cognitive-Behavioral Therapy Group for Youth with Anxiety Disorders:

Part 1, The Case of Erik

I. Lundkvist-Houndoumadi \& M. Thastum

Pragmatic Case Studies in Psychotherapy, http://pcsp.libraries.rutgers.edu

Volume 9, Module 2, Article 2, pp. 122-178, 06-26-13 [copyright by authors]

\section{Table 4. The Cool Kids Program as Implemented at the Aarhus Children's Anxiety Clinic}

\begin{tabular}{|c|c|c|c|c|}
\hline Session \# & Children alone & Parents alone & Family together & Homework \\
\hline $\begin{array}{l}1(04 / 16 / 09) \\
\text { Introduction } \\
\text { to program } \\
\text { and learning } \\
\text { about } \\
\text { anxiety }\end{array}$ & $\begin{array}{l}\text { Children are introduced } \\
\text { to the links between } \\
\text { feelings and thoughts. }\end{array}$ & $\begin{array}{l}\text { Parents are introduced } \\
\text { to the program and the } \\
\text { nature and causes of } \\
\text { anxiety. Goals are } \\
\text { discussed and set. }\end{array}$ & $\begin{array}{l}\text { The families sign } \\
\text { a contract } \\
\text { indicating that } \\
\text { they will put } \\
\text { continuous effort } \\
\text { in the program } \\
\text { and as a reward } \\
\text { they will do } \\
\text { something nice as } \\
\text { a family. }\end{array}$ & $\begin{array}{l}\text { Children: exercises } \\
\text { where they should } \\
\text { learn to identify and } \\
\text { separate thoughts and } \\
\text { feelings in situations. } \\
\text { Parents: register } \\
\text { what they know } \\
\text { about their child's } \\
\text { worries. }\end{array}$ \\
\hline $\begin{array}{l}2(7)^{*} \\
\text { Detective } \\
\text { thinking }\end{array}$ & $\begin{array}{l}\text { Introduction to cognitive } \\
\text { restructuring (detective } \\
\text { thinking). }\end{array}$ & $\begin{array}{l}\text { Introduction to } \\
\text { cognitive restructuring } \\
\text { (detective thinking). }\end{array}$ & $\begin{array}{l}\text { Each child and } \\
\text { parents unit } \\
\text { explain what they } \\
\text { have learned and } \\
\text { plan their } \\
\text { homework. }\end{array}$ & $\begin{array}{l}\text { Children: practice } \\
\text { detective thinking. } \\
\text { Parents: practice } \\
\text { cognitive } \\
\text { restructuring. }\end{array}$ \\
\hline $\begin{array}{l}3(7) \\
\text { Child } \\
\text { management } \\
\text { techniques }\end{array}$ & $\begin{array}{l}\text { Practice detective } \\
\text { thinking- on their own } \\
\text { and other worrisome } \\
\text { thoughts. Introduction to } \\
\text { how they can reward } \\
\text { themselves. }\end{array}$ & $\begin{array}{l}\text { Child management } \\
\text { strategies: encouraging } \\
\text { courageous vs. anxious } \\
\text { behavior, the role of } \\
\text { reassurance in } \\
\text { maintaining anxiety, } \\
\text { ways to reduce } \\
\text { anxiety, the } \\
\text { importance of } \\
\text { consistency between } \\
\text { expectations of parents } \\
\text { etc. }\end{array}$ & $\begin{array}{l}\text { Children explain } \\
\text { what they have } \\
\text { learned and they } \\
\text { are reminded of } \\
\text { their homework. }\end{array}$ & $\begin{array}{l}\text { Children: reward } \\
\text { themselves and } \\
\text { practice detective } \\
\text { thinking. } \\
\text { Parents: register their } \\
\text { reactions to their } \\
\text { child's negative and } \\
\text { positive behavior. }\end{array}$ \\
\hline $\begin{array}{l}4(7) \\
\text { Exposures } \\
\text { and } \\
\text { developing } \\
\text { hierarchies }\end{array}$ & $\begin{array}{l}\text { An introduction to the } \\
\text { principles of exposures } \\
\text { and starting to develop } \\
\text { relevant hierarchies } \\
\text { (stepladders). }\end{array}$ & $\begin{array}{l}\text { The principles of } \\
\text { exposure and } \\
\text { stepladders. }\end{array}$ & $\begin{array}{l}\text { Making a fears } \\
\text { and worries list } \\
\text { and creation of } \\
\text { the first } \\
\text { stepladder. }\end{array}$ & $\begin{array}{l}\text { Finishing the } \\
\text { stepladders' form and } \\
\text { starting exposure. }\end{array}$ \\
\hline $\begin{array}{l}5(7) \\
\text { Revising } \\
\text { hierarchies } \\
\text { and worry } \\
\text { surfing }\end{array}$ & $\begin{array}{l}\text { Revising the } \\
\text { stepladders. Introduction } \\
\text { to worry surfing. }\end{array}$ & $\begin{array}{l}\text { Creative exposures. } \\
\text { Introduction to worry } \\
\text { surfing. }\end{array}$ & $\begin{array}{l}\text { New stepladders } \\
\text { are created. }\end{array}$ & $\begin{array}{l}\text { Do exposures based } \\
\text { on the stepladders } \\
\text { made. }\end{array}$ \\
\hline
\end{tabular}

* Number of days since last session in parenthesis. 
A "Cool Kids" Cognitive-Behavioral Therapy Group for Youth with Anxiety Disorders:

Part 1, The Case of Erik

I. Lundkvist-Houndoumadi \& M. Thastum

Pragmatic Case Studies in Psychotherapy, http://pcsp.libraries.rutgers.edu

Volume 9, Module 2, Article 2, pp. 122-178, 06-26-13 [copyright by authors]

Table 4 (continued)

\begin{tabular}{|c|c|c|c|c|}
\hline Session \# & Children alone & Parents alone & Family together & Homework \\
\hline $\begin{array}{l}6(7)^{*} \\
\text { Exposures } \\
\text { and problem } \\
\text { solving }\end{array}$ & $\begin{array}{l}\text { Introduction to problem } \\
\text { solving and talking } \\
\text { about difficulties in } \\
\text { exposures. }\end{array}$ & $\begin{array}{l}\text { Discussing possible } \\
\text { difficulties } \\
\text { encountered in } \\
\text { exposures. } \\
\text { Introduction to } \\
\text { problem solving. }\end{array}$ & $\begin{array}{l}\text { Planning of } \\
\text { stepladder. }\end{array}$ & $\begin{array}{l}\text { Children: exposures } \\
\text { Parents: Assessing } \\
\text { social skills of their } \\
\text { children and } \\
\text { monitoring. }\end{array}$ \\
\hline $\begin{array}{l}7(7) \\
\text { In session } \\
\text { exposures }\end{array}$ & $\begin{array}{l}\text { In session exposures in } \\
\text { shopping mall }\end{array}$ & $\begin{array}{l}\text { Child does exposures, } \\
\text { while parents coach, } \\
\text { assisted by student } \\
\text { therapists if needed. }\end{array}$ & & Exposures \\
\hline $\begin{array}{l}8(14) \\
\text { Social skills } \\
\text { and } \\
\text { assertivenes } \\
\text { s training }\end{array}$ & $\begin{array}{l}\text { Introduction to the } \\
\text { differences between } \\
\text { assertive, anxious and } \\
\text { aggressive behavior. } \\
\text { Practice being assertive } \\
\text { through role playing. }\end{array}$ & $\begin{array}{l}\text { Introduction to social } \\
\text { skills and assertiveness } \\
\text { training. }\end{array}$ & & $\begin{array}{l}\text { Children: } \\
\text { Do exposures and } \\
\text { practice assertive } \\
\text { behavior } \\
\text { Parents: assist } \\
\text { children in } \\
\text { practicing their } \\
\text { homework } \\
\text { completing } \\
\text { checklists. }\end{array}$ \\
\hline $\begin{array}{l}9(7) \\
\text { Review } \\
\text { progress and } \\
\text { plan future } \\
\text { goals }\end{array}$ & $\begin{array}{l}\text { Review and problem } \\
\text { solve last practice task. } \\
\text { Review progress made } \\
\text { in therapy and how they } \\
\text { could help other } \\
\text { children. }\end{array}$ & $\begin{array}{l}\text { Review goals set at the } \\
\text { first session. }\end{array}$ & $\begin{array}{l}\text { Parents write in } \\
\text { children's } \\
\text { workbooks what } \\
\text { they are proud the } \\
\text { children have } \\
\text { achieved. }\end{array}$ & Exposures \\
\hline $\begin{array}{l}10(7) \\
\text { Relapse } \\
\text { management }\end{array}$ & $\begin{array}{l}\text { Review and problem } \\
\text { solved during last } \\
\text { practice task and plan } \\
\text { for the future. }\end{array}$ & $\begin{array}{l}\text { Maintenance and set } \\
\text { backs }\end{array}$ & $\begin{array}{l}\text { Celebrate the } \\
\text { completion of the } \\
\text { program. Children } \\
\text { are handed out } \\
\text { diplomas. }\end{array}$ & $\begin{array}{l}\text { Keep on working } \\
\text { on their set goals. }\end{array}$ \\
\hline $\begin{array}{l}\text { Follow-up } \\
\text { 1/ Booster } \\
\text { (3 months) }\end{array}$ & $\begin{array}{l}\text { Talk about what the } \\
\text { children had achieved } \\
\text { since the end of } \\
\text { treatment. Review the } \\
\text { program components. }\end{array}$ & $\begin{array}{l}\text { ADIS-P interview with } \\
\text { parents, while children } \\
\text { complete } \\
\text { questionnaires. } \\
\text { Discussion about } \\
\text { progress or setbacks } \\
\text { and exchange of } \\
\text { possible solutions to } \\
\text { the encountered } \\
\text { difficulties. }\end{array}$ & $\begin{array}{l}\text { Celebrating and } \\
\text { free talk. }\end{array}$ & \\
\hline $\begin{array}{l}\text { Follow-up } \\
\text { 2/ } \\
\text { Interview } \\
\text { (15 months) }\end{array}$ & $\begin{array}{l}\text { Interview with child } \\
\text { (parents complete the } \\
\text { quantitative part of the } \\
\text { interview) }\end{array}$ & $\begin{array}{l}\text { Interview with parents } \\
\text { ADIS-P }\end{array}$ & & \\
\hline
\end{tabular}

*Number of days since last session in parenthesis. 
Table 5. Quantitative Data for Erik at Four Points in Time

\begin{tabular}{|c|c|c|c|c|c|c|c|c|c|c|c|c|}
\hline \multirow[b]{2}{*}{ Scale } & \multicolumn{3}{|c|}{\begin{tabular}{|c|} 
Pre-treatment \\
\end{tabular}} & \multicolumn{3}{|c|}{ Post-treatment } & \multicolumn{3}{|c|}{ 3-month follow-up } & \multicolumn{3}{|c|}{ 15-month follow-up } \\
\hline & Mother & Father & Child & Mother & Father & Child & Mother & Father & Child & Mother & Father & Child \\
\hline \multicolumn{13}{|l|}{ SDQ } \\
\hline Emotional problems & 6* & & $7 *$ & $2 \# a$ & $3 \# a$ & & $1 \#^{\mathrm{a}} \mathrm{q}^{\mathrm{a}}$ & $1 \#^{\mathrm{a}} a^{\mathrm{ab}}$ & $9 a^{a}$ & 1 & $0 a^{b}$ & $1 \#^{\mathrm{C}} \mathrm{a}^{\mathrm{C}}$ \\
\hline Hyperactivity & 5 & & 2 & 3 & 3 & & 3 & 3 & 1 & 2 & 3 & $5 \#^{C} a^{C}$ \\
\hline Behavior prblms & 3 & & 3 & 10 & 10 & & $1 \mathrm{a}^{\mathrm{a}}$ & $1 \mathrm{a}^{\mathrm{a}}$ & $5 q^{\mathrm{a}}$ & 2 & 0 & $2 a^{c}$ \\
\hline Prblms with peers & 3 & & 3 & 3 & 4 & & $1 \mathrm{a}^{\mathrm{ab}}$ & $1 \#^{\mathrm{b}} \mathrm{a}^{\mathrm{ab}}$ & $1 \mathrm{a}^{\mathrm{a}}$ & 2 & $0 \#^{b} a^{b}$ & 0 \\
\hline TOTAL & $17 *$ & & 15 & 90 & 110 & & $6 \#^{\mathrm{a}} \mathrm{a}^{\mathrm{a}}$ & $6 \#^{a} a^{a}$ & 16 & 7 & $3 a^{b}$ & $8 \#^{C} a^{c}$ \\
\hline Prosocial behavior & 9 & & 10 & 10 & 8 & & 10 & 8 & $2 \#^{\mathrm{a}} \mathrm{a}^{\mathrm{a}}$ & $7 \#^{\mathrm{bc}} \mathrm{ac}^{\mathrm{bc}}$ & 8 & $9 \#^{\mathrm{c}}$ \\
\hline & & & & & & & & & & & & \\
\hline \multicolumn{13}{|l|}{ BYI } \\
\hline Self-concept & 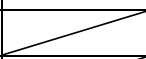 & 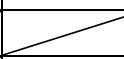 & 34 & 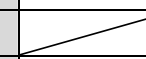 & 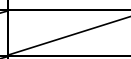 & 34 & 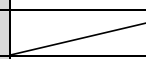 & 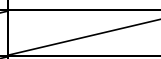 & $44 \#^{\mathrm{ab}} \mathrm{a}^{\mathrm{ab}}$ & 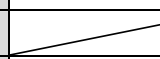 & 2 & $36 \#^{\mathrm{c}} \mathrm{a}^{\mathrm{C}}$ \\
\hline Anxiety & 4 & 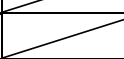 & 11 & 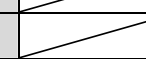 & 7 & 14 & 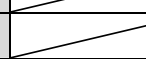 & 2 & $8 \#^{\mathrm{b}}$ & 2 & 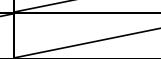 & 13 \\
\hline Depression & 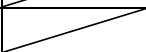 & & 9 & 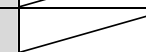 & 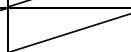 & $1 \# a$ & 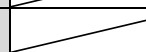 & 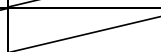 & $8 \#^{\mathrm{b}} \mathrm{a}^{\mathrm{b}}$ & 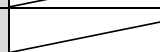 & 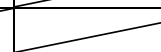 & 7 \\
\hline Anger & 7 & & 12 & 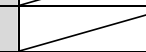 & 4 & 16 & 2 & 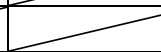 & $10 \#^{\mathrm{b}}$ & 2 & 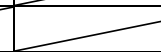 & $9 \#^{b} a^{b}$ \\
\hline Disruptive behavior & & & 4 & 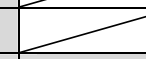 & & 6 & 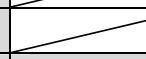 & 2 & - & 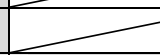 & 2 & - \\
\hline & & & & & & & & & & & & \\
\hline \multicolumn{13}{|l|}{ SCAS } \\
\hline Panic/agoraphobia & 1 & 0 & 2 & 0 & 0 & 2 & 0 & 0 & 1 & 1 & 0 & 0 \\
\hline Generalized anxiety & 6* & 5 & $8^{*}$ & $3 \# a$ & $2 \# a$ & $4 \# a$ & $2 \#^{\mathrm{a}} \mathrm{q}^{\mathrm{a}}$ & $2 \#^{\mathrm{a}} \mathrm{a}^{\mathrm{a}}$ & $4 \#^{\mathrm{a}} \mathrm{a}^{\mathrm{a}}$ & $3 \#^{\mathrm{a}} \mathrm{a}^{\mathrm{a}}$ & 3 & $5 \mathrm{a}^{\mathrm{a}}$ \\
\hline Social phobia & 7 & $8^{*}$ & $7 *$ & $2 \# a$ & $4 \# a$ & $4 a$ & $4 \mathrm{a}^{\mathrm{a}}$ & $4 \#^{\mathrm{a}} \mathrm{a}^{\mathrm{a}}$ & $3 \#^{\mathrm{a}} \mathrm{q}^{\mathrm{a}}$ & $2 \#^{a} a^{a}$ & $3 \#^{\mathrm{a}} \mathrm{a}^{\mathrm{a}}$ & $4 a^{a}$ \\
\hline Anx. Physical Injury & 2 & 3 & 4 & 3 & 3 & $5 *$ & 1 & 1 & 2 & 1 & $0 \mathrm{a}^{\mathrm{ab}}$ & $2 a^{b}$ \\
\hline OCD & 0 & $5 *$ & 4 & 0 & $0 \# a$ & $0 \# a$ & 0 & $0 \#^{\mathrm{a}} \mathrm{q}^{\mathrm{a}}$ & $0 \#^{\mathrm{a}} \mathrm{a}^{\mathrm{a}}$ & 0 & $0 \#^{\mathrm{a}} \mathrm{a}^{\mathrm{a}}$ & $0 \#^{\mathrm{a}} \mathrm{a}^{\mathrm{a}}$ \\
\hline Separation anxiety & \begin{tabular}{|l|}
2 \\
\end{tabular} & 4 & 3 & 2 & 2 & 2 & 2 & $5 \#^{b} a^{b}$ & 3 & 1 & $1 \#^{\mathrm{a}} \mathrm{a}^{\mathrm{a}}$ & 1 \\
\hline TOTAL & 18 & 25 & $28^{*}$ & $10 \#$ & $11 \# a$ & 17 \# & $9 \#^{\mathrm{a}} \mathrm{o}^{\mathrm{a}}$ & $12 \#^{\mathrm{a}} \mathrm{a}^{\mathrm{a}}$ & $13 \#^{\mathrm{a}} \mathrm{a}^{\mathrm{a}}$ & $8 \#^{\mathrm{a}} \mathrm{a}^{\mathrm{a}}$ & $7 \#^{\mathrm{a}} \mathrm{a}^{\mathrm{a}}$ & $12 \#^{\mathrm{a}} \mathrm{a}^{\mathrm{a}}$ \\
\hline \multicolumn{13}{|l|}{ CALIS } \\
\hline Child interference & 15 & 8 & 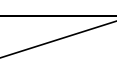 & $6 \# a$ & 7 & 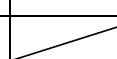 & $2 \#^{\mathrm{a}}$ & 5 & 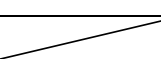 & $2 \#^{\mathrm{a}} \mathrm{a}^{\mathrm{a}}$ & 2 & 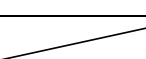 \\
\hline Family interference & 13 & 5 & 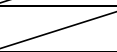 & $3 \# a$ & 3 & 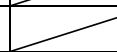 & $0 \#^{\mathrm{a}}$ & 2 & $\infty$ & 6 & 0 & 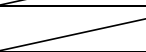 \\
\hline Child reported & 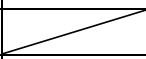 & 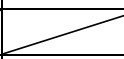 & 4 & 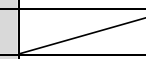 & 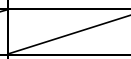 & 3 & 2 & 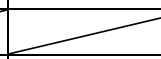 & $29+\#^{b} a^{b}$ & - & 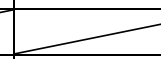 & $10 \#^{\mathrm{C}} \mathrm{a}^{\mathrm{c}}$ \\
\hline & & & & & & & & & & & & \\
\hline
\end{tabular}

NATURE OR SIZE OF CHANGE: *clinical population level; \#statistically significant change; alarge effect (positive change more than one SD of the scale); clinical change (going from a clinical to a non-clinical level on a scale); negative change

POINTS OF CHANGE: compared to ${ }^{a}$ pre-treatment, ${ }^{b}$ post-treatment, ${ }^{c}$ 3-month follow-up 
A "Cool Kids" Cognitive-Behavioral Therapy Group for Youth with Anxiety Disorders:

Part 1, The Case of Erik

I. Lundkvist-Houndoumadi \& M. Thastum

Pragmatic Case Studies in Psychotherapy, http://pcsp.libraries.rutgers.edu

Volume 9, Module 2, Article 2, pp. 122-178, 06-26-13 [copyright by authors]

Table 6. Diagnoses at Different Points in Time

\begin{tabular}{|l|l|l|}
\hline Diagnosis at the Time of Referral (CRS) & \multicolumn{1}{|c|}{$\begin{array}{c}\text { Diagnosis } \\
\text { at 3-Month } \\
\text { Follow-Up }\end{array}$} & $\begin{array}{l}\text { Diagnosis at 15- } \\
\text { Month Follow-Up }\end{array}$ \\
\hline $\begin{array}{l}\text { Generalized Anxiety Disorder (8*) } \\
\text { Specific Phobia of Blood-Injection-Injury Type }\left(8^{*}\right) \\
\text { Social Phobia (7*) }\end{array}$ & None & None \\
Separation Anxiety Disorder (6-7*) & & \\
Specific Phobia of Animal Type (bees) $\left(6^{*}\right)$ & & \\
\hline
\end{tabular}

*Clinical Severity Rating from the ADIS-P, from 0, "no worry, no fear," to 8, "constantly worried/extreme fear" 
Part 1, The Case of Erik

I. Lundkvist-Houndoumadi \& M. Thastum

Pragmatic Case Studies in Psychotherapy, http://pcsp.libraries.rutgers.edu

Volume 9, Module 2, Article 2, pp. 122-178, 06-26-13 [copyright by authors]

\section{Table 7. The Structure of the Cool Kids Program}

Note: If a single meeting involves different segments-e.g., if everyone convenes in one room and later the children and the student therapists go to another room - then each of the segments is entered on a different line. For example, if the fifth session involved three segments: everyone together, then children and parents split, and then everyone together, this would be entered as three meetings, labelled 5A, 5B, and 5C.

\begin{tabular}{|c|c|c|c|c|c|c|c|c|c|c|}
\hline $\begin{array}{l}\text { Meeting } \\
\text { Number }\end{array}$ & $\begin{array}{l}\text { Number of } \\
\text { Days Since } \\
\text { First } \\
\text { Meeting }\end{array}$ & $\begin{array}{l}\text { Type of } \\
\text { Meeting }\end{array}$ & $\begin{array}{l}\text { Type of } \\
\text { segment }\end{array}$ & $\begin{array}{l}\text { Number of } \\
\text { Child Clients } \\
\text { at the Meeting }\end{array}$ & $\begin{array}{l}\text { Number of } \\
\text { Parents at } \\
\text { the Meeting }\end{array}$ & $\begin{array}{l}\text { Number of } \\
\text { Senior } \\
\text { Psychologists } \\
\text { at the Meeting }\end{array}$ & $\begin{array}{l}\text { Number of } \\
\text { Student } \\
\text { Therapists at the } \\
\text { Meeting }\end{array}$ & $\begin{array}{l}\text { Erik } \\
\text { Attended } \\
\text { Meeting }\end{array}$ & $\begin{array}{l}\text { Mia } \\
\text { Attended } \\
\text { Meeting }\end{array}$ & $\begin{array}{l}\text { Ib Attended } \\
\text { Meeting }\end{array}$ \\
\hline $1 \mathrm{~A}$ & 0 & assessment & Parents & 0 & 2 & 1 & 1 & no & yes & yes \\
\hline $1 \mathrm{~B}$ & 0 & assessment & Child & 1 & 0 & 0 & 1 & yes & no & no \\
\hline 2 & 7 & assessment & Parents & 0 & 2 & 1 & 1 & no & yes & yes \\
\hline $3 \mathrm{~A}$ & 24 & Therapy & all together & 6 & 12 & 1 & 8 & yes & no & no \\
\hline $3 \mathrm{~B}$ & 24 & Therapy & Children & 6 & 0 & 1 & 8 & yes & no & no \\
\hline $3 C$ & 24 & Therapy & Parents & 0 & 12 & 1 & 6 & no & yes & yes \\
\hline $3 \mathrm{D}$ & 24 & Therapy & all together & 6 & 12 & 1 & 8 & yes & yes & yes \\
\hline $4 \mathrm{~A}$ & 31 & Therapy & all together & 6 & 12 & 1 & 8 & yes & yes & yes \\
\hline $4 \mathrm{~B}$ & 31 & Therapy & Children & 6 & 0 & 1 & 8 & yes & no & no \\
\hline $4 \mathrm{C}$ & 31 & Therapy & Parents & 0 & 12 & 1 & 6 & no & yes & yes \\
\hline $4 \mathrm{D}$ & 31 & Therapy & all together & 6 & 12 & 1 & 8 & yes & yes & yes \\
\hline $5 \mathrm{~A}$ & 38 & Therapy & all together & 6 & 12 & 1 & 8 & yes & yes & yes \\
\hline $5 B$ & 38 & Therapy & Children & 6 & 0 & 1 & 8 & yes & no & no \\
\hline $5 \mathrm{C}$ & 38 & Therapy & Parents & 0 & 12 & 1 & 6 & no & yes & yes \\
\hline $5 \mathrm{D}$ & 38 & Therapy & all together & 6 & 12 & 1 & 8 & yes & yes & yes \\
\hline $6 \mathrm{~A}$ & 45 & Therapy & all together & 5 & 12 & 1 & 7 & no & no & yes \\
\hline $6 \mathrm{~B}$ & 45 & Therapy & Children & 5 & 0 & 1 & 7 & no & no & yes \\
\hline $6 \mathrm{C}$ & 45 & Therapy & Parents & 0 & 12 & 1 & 5 & no & no & yes \\
\hline $6 \mathrm{D}$ & 45 & Therapy & all together & 5 & 12 & 1 & 7 & no & no & yes \\
\hline 7 & 51 & Therapy & house visit & 1 & 2 & 0 & 2 & yes & yes & Yes \\
\hline
\end{tabular}


A "Cool Kids" Cognitive-Behavioral Therapy Group for Youth with Anxiety Disorders:

Part 1, The Case of Erik

I. Lundkvist-Houndoumadi \& M. Thastum

Pragmatic Case Studies in Psychotherapy, http://pcsp.libraries.rutgers.edu

Volume 9, Module 2, Article 2, pp. 122-178, 06-26-13 [copyright by authors]

Table 7 (continued)

\begin{tabular}{|c|c|c|c|c|c|c|c|c|c|c|}
\hline $\begin{array}{l}\text { Meeting } \\
\text { Number }\end{array}$ & $\begin{array}{l}\text { Number of } \\
\text { Days Since } \\
\text { First } \\
\text { Meeting }\end{array}$ & $\begin{array}{l}\text { Type of } \\
\text { Meeting }\end{array}$ & $\begin{array}{l}\text { Type of } \\
\text { segment }\end{array}$ & $\begin{array}{l}\text { Number of } \\
\text { Child Clients } \\
\text { at the Meeting }\end{array}$ & $\begin{array}{l}\text { Number of } \\
\text { Parents at } \\
\text { the Meeting }\end{array}$ & $\begin{array}{l}\text { Number of } \\
\text { Senior } \\
\text { Psychologists } \\
\text { at the Meeting }\end{array}$ & $\begin{array}{l}\text { Number of } \\
\text { Student } \\
\text { Therapists at the } \\
\text { Meeting }\end{array}$ & $\begin{array}{l}\text { Erik } \\
\text { Attended } \\
\text { Meeting }\end{array}$ & $\begin{array}{l}\text { Mia } \\
\text { Attended } \\
\text { Meeting }\end{array}$ & $\begin{array}{l}\text { Ib Attended } \\
\text { Meeting }\end{array}$ \\
\hline $8 \mathrm{~A}$ & 52 & Therapy & all together & 5 & 12 & 1 & 8 & yes & no & No \\
\hline $8 B$ & 52 & Therapy & children & 5 & 0 & 1 & 8 & yes & yes & Yes \\
\hline $8 \mathrm{C}$ & 52 & Therapy & parents & 0 & 12 & 1 & 6 & no & yes & Yes \\
\hline $8 \mathrm{D}$ & 52 & Therapy & all together & 5 & 12 & 1 & 8 & yes & yes & Yes \\
\hline $9 \mathrm{~A}$ & 59 & Therapy & all together & 5 & 12 & 1 & 8 & yes & yes & No \\
\hline $9 B$ & 59 & Therapy & children & 5 & 0 & 1 & 8 & yes & no & No \\
\hline $9 \mathrm{C}$ & 59 & Therapy & parents & 0 & 12 & 1 & 6 & no & yes & No \\
\hline 9D & 59 & Therapy & all together & 5 & 12 & 1 & 8 & yes & yes & No \\
\hline $10 \mathrm{~A}$ & 66 & Therapy & all together & 6 & 12 & 1 & 8 & yes & yes & Yes \\
\hline $10 \mathrm{~B}$ & 66 & Therapy & $\begin{array}{l}\text { child + } \\
\text { parents }\end{array}$ & 1 & 2 & 0 & 2 & yes & yes & Yes \\
\hline $10 \mathrm{C}$ & 66 & Therapy & all together & 6 & 12 & 1 & 8 & yes & yes & Yes \\
\hline $11 \mathrm{~A}$ & 80 & Therapy & all together & 6 & 12 & 1 & 8 & yes & yes & Yes \\
\hline $11 \mathrm{~B}$ & 80 & Therapy & children & 6 & 0 & 1 & 8 & yes & no & No \\
\hline $11 \mathrm{C}$ & 80 & Therapy & parents & 0 & 12 & 1 & 8 & no & yes & Yes \\
\hline $11 \mathrm{D}$ & 80 & Therapy & all together & 6 & 12 & 1 & 8 & yes & yes & Yes \\
\hline $12 \mathrm{~A}$ & 87 & Therapy & all together & 6 & 12 & 1 & 7 & yes & yes & Yes \\
\hline $12 \mathrm{~B}$ & 87 & Therapy & children & 6 & 0 & 1 & 7 & yes & no & No \\
\hline $12 \mathrm{C}$ & 87 & Therapy & parents & 0 & 12 & 1 & 7 & no & yes & Yes \\
\hline $12 \mathrm{D}$ & 87 & Therapy & all together & 6 & 12 & 1 & 7 & yes & yes & Yes \\
\hline $13 \mathrm{~A}$ & 94 & Therapy & all together & 6 & 12 & 1 & 8 & yes & yes & yes \\
\hline 13B & 94 & Therapy & children & 6 & 0 & 1 & 8 & yes & no & No \\
\hline $13 \mathrm{C}$ & 94 & Therapy & parents & 0 & 12 & 1 & 8 & no & yes & Yes \\
\hline $13 \mathrm{D}$ & 94 & Therapy & all together & 6 & 12 & 1 & 8 & yes & yes & Yes \\
\hline $14 \mathrm{~A}$ & 197 & follow up & all together & 6 & 12 & 1 & 8 & yes & yes & Yes \\
\hline 14B & 197 & follow up & parents & 6 & 2 & 0 & 6 & no & yes & Yes \\
\hline $14 \mathrm{C}$ & 197 & follow up & children & 0 & 12 & 1 & 8 & yes & no & No \\
\hline $14 \mathrm{C}$ & 197 & follow up & all together & 0 & 12 & 1 & 8 & yes & yes & Yes \\
\hline
\end{tabular}


A "Cool Kids" Cognitive-Behavioral Therapy Group for Youth with Anxiety Disorders:

Part 1, The Case of Erik

I. Lundkvist-Houndoumadi \& M. Thastum

Pragmatic Case Studies in Psychotherapy, http://pcsp.libraries.rutgers.edu

Volume 9, Module 2, Article 2, pp. 122-178, 06-26-13 [copyright by authors]

\section{Table 8. Evaluation of Treatment Goals}

From the Parents' Workbook:

\begin{tabular}{|c|c|}
\hline $\begin{array}{l}\text { What items has your child begun to } \\
\text { achieve or completed? }\end{array}$ & $\begin{array}{l}\text { Of the behaviors that you wanted your } \\
\text { child to stop doing, how often are they } \\
\text { doing those things now? }\end{array}$ \\
\hline $\begin{array}{l}\text { 1. Erik can ride his bike and on his own get } \\
\text { from A-B. } \\
\text { 2. Future goal: being able to walk on his } \\
\text { own } \\
\text { 3. Can be home alone. } \\
\text { 4. Future goal: be able to do that for longer } \\
\text { time intervals } \\
\text { 5. Can go to shops with others. } \\
\text { 6. Future goal: be able to go to shops alone }\end{array}$ & $\begin{array}{l}\text { Behavior: Think negative thoughts } \\
\text { How often: 0-1 a week }\end{array}$ \\
\hline \multicolumn{2}{|c|}{$\begin{array}{l}\text { What goals have you personally achieved? (completed by mother only) } \\
\text { 1. Not to transfer my anxiety to Erik } \\
\text { 2. Not always try and reassure him everything will be fine when something is difficult } \\
\text { 3. Push him a little bit }\end{array}$} \\
\hline
\end{tabular}


A "Cool Kids" Cognitive-Behavioral Therapy Group for Youth with Anxiety Disorders:

Part 1, The Case of Erik

I. Lundkvist-Houndoumadi \& M. Thastum

Pragmatic Case Studies in Psychotherapy, http://pcsp.libraries.rutgers.edu

Volume 9, Module 2, Article 2, pp. 122-178, 06-26-13 [copyright by authors]

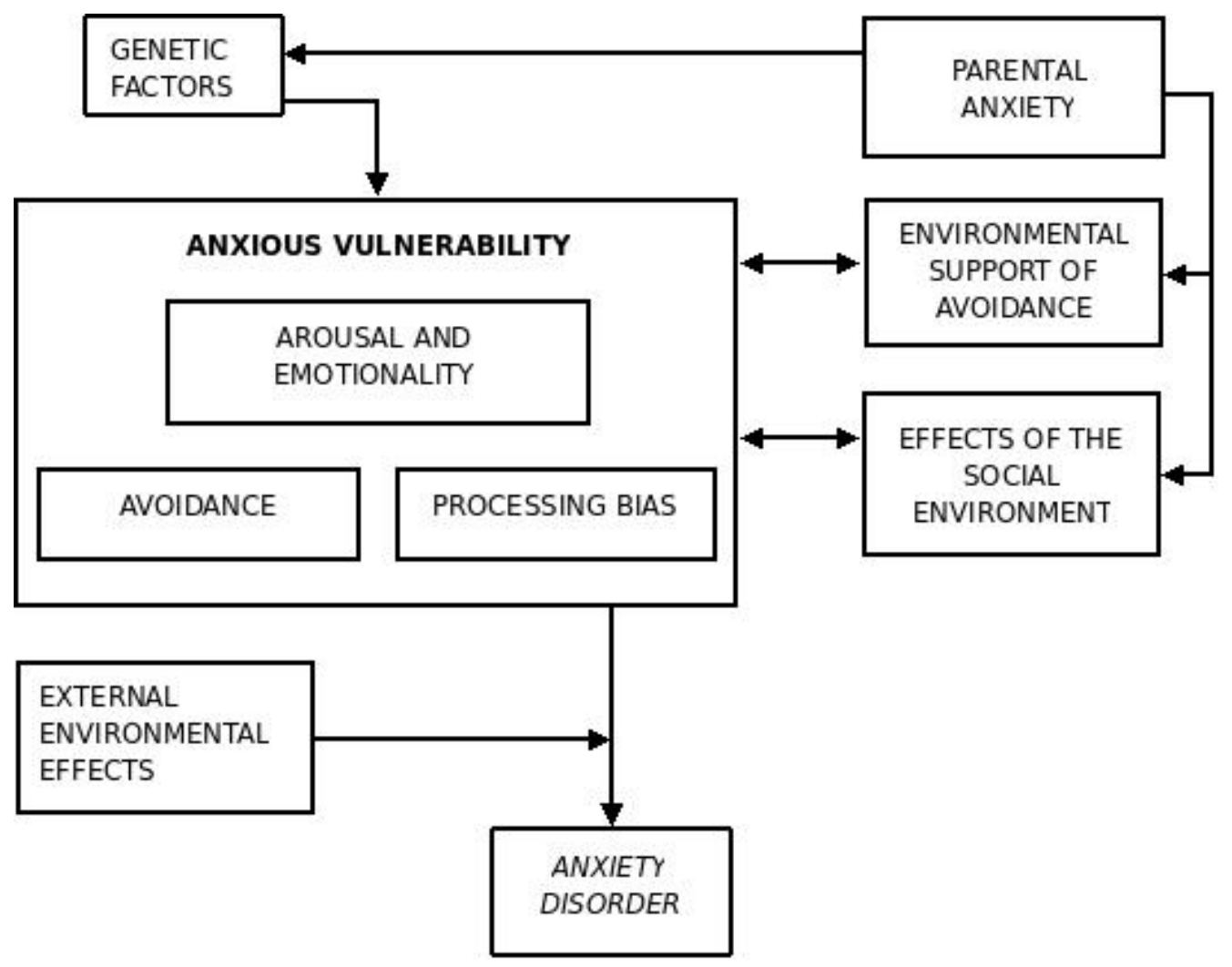

Figure 1. A Model Illustrating the Development of Anxiety (Rapee, 2001) 
A "Cool Kids" Cognitive-Behavioral Therapy Group for Youth with Anxiety Disorders:

Part 1, The Case of Erik

I. Lundkvist-Houndoumadi \& M. Thastum

Pragmatic Case Studies in Psychotherapy, http://pcsp.libraries.rutgers.edu

Volume 9, Module 2, Article 2, pp. 122-178, 06-26-13 [copyright by authors]

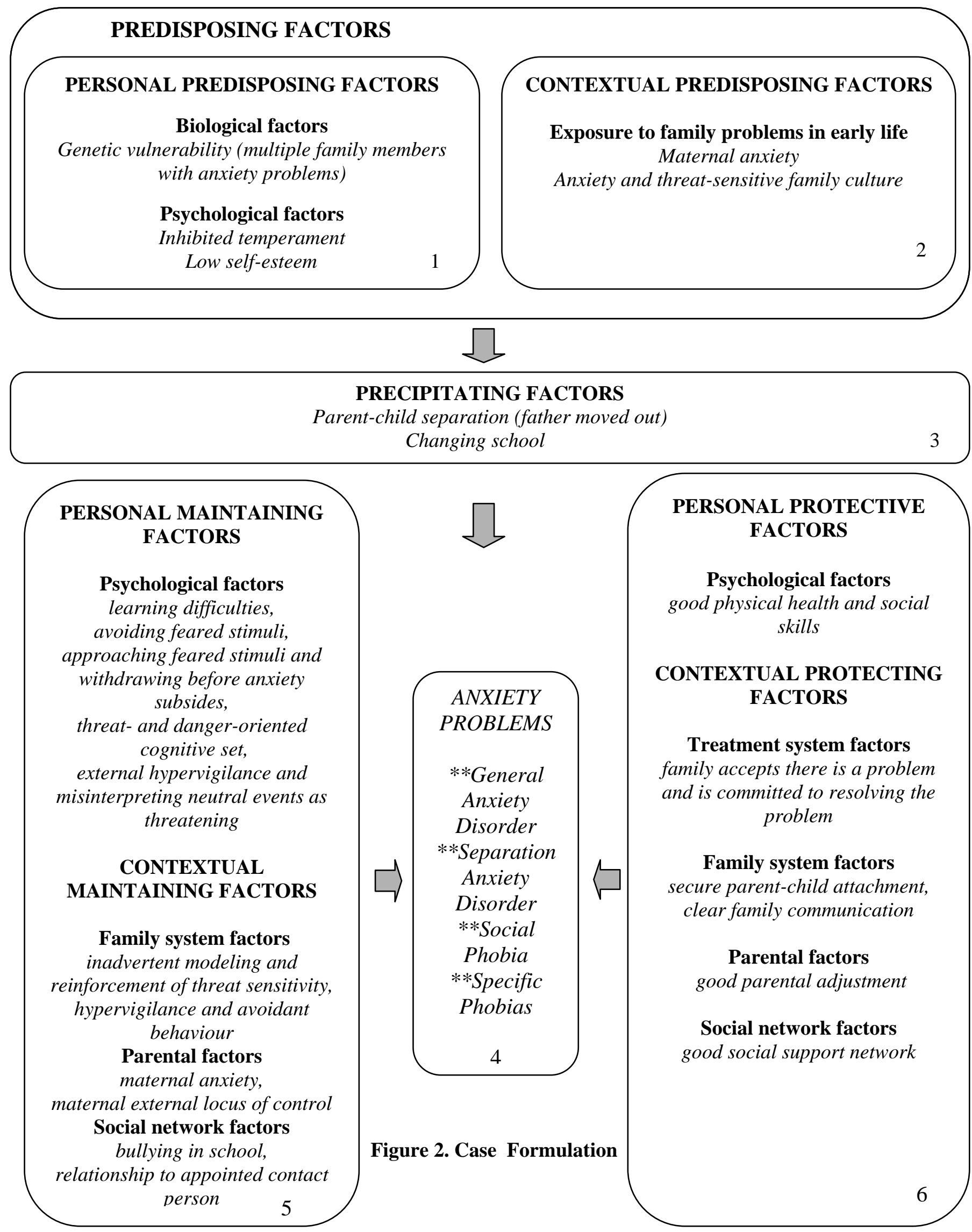


A "Cool Kids" Cognitive-Behavioral Therapy Group for Youth with Anxiety Disorders:

Part 1, The Case of Erik

I. Lundkvist-Houndoumadi \& M. Thastum

Pragmatic Case Studies in Psychotherapy, http://pcsp.libraries.rutgers.edu

Volume 9, Module 2, Article 2, pp. 122-178, 06-26-13 [copyright by authors]

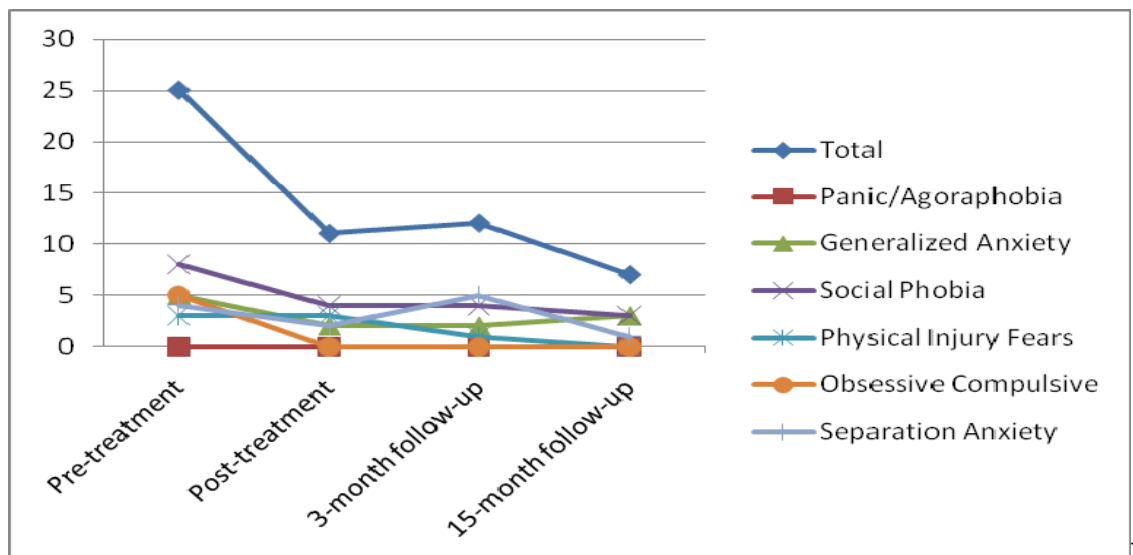

Father's ratings

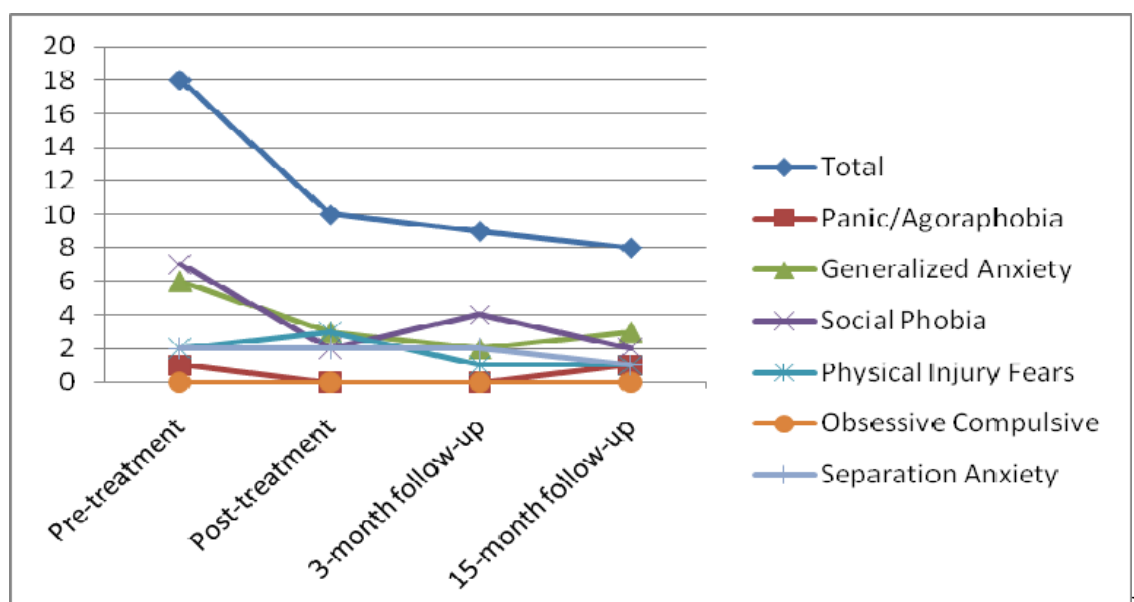

Mother's ratings

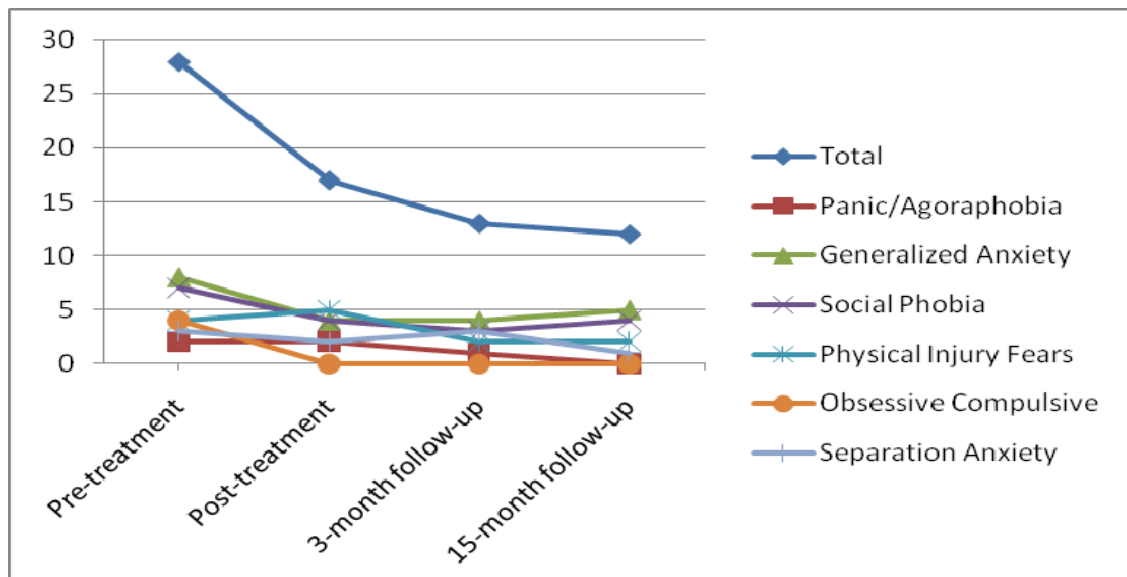

Child's ratings

Figures 3-5. Ratings on the SCAS at Different Points in Time 
A "Cool Kids" Cognitive-Behavioral Therapy Group for Youth with Anxiety Disorders:

Part 1, The Case of Erik

I. Lundkvist-Houndoumadi \& M. Thastum

Pragmatic Case Studies in Psychotherapy, http://pcsp.libraries.rutgers.edu

Volume 9, Module 2, Article 2, pp. 122-178, 06-26-13 [copyright by authors]
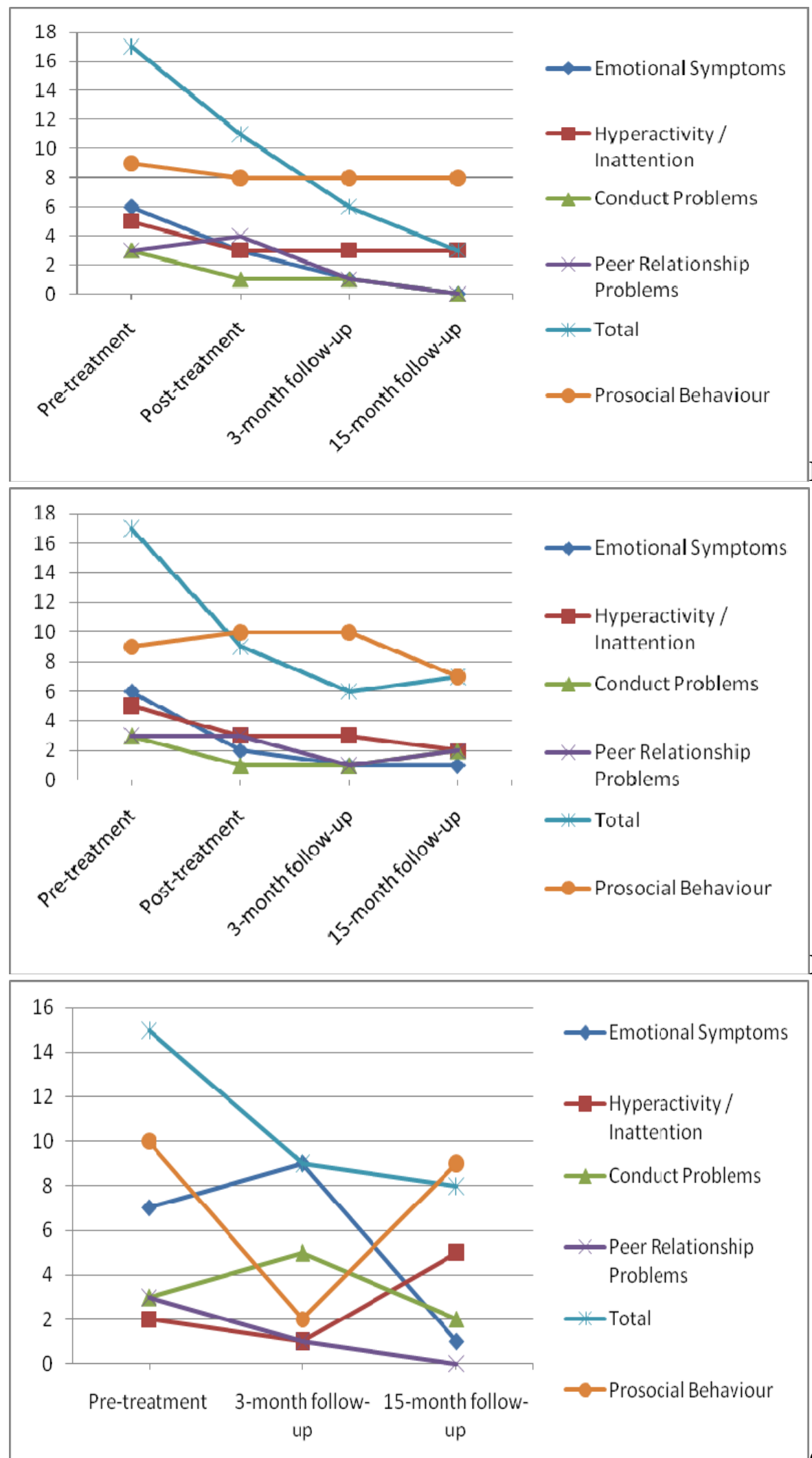

Mother's ratings

Father's ratings

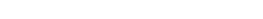

Child's ratings

Figures 6-8. Ratings on the SDQ at Different Points in Time 
A "Cool Kids" Cognitive-Behavioral Therapy Group for Youth with Anxiety Disorders:

Part 1, The Case of Erik

I. Lundkvist-Houndoumadi \& M. Thastum

Pragmatic Case Studies in Psychotherapy, http://pcsp.libraries.rutgers.edu

Volume 9, Module 2, Article 2, pp. 122-178, 06-26-13 [copyright by authors]

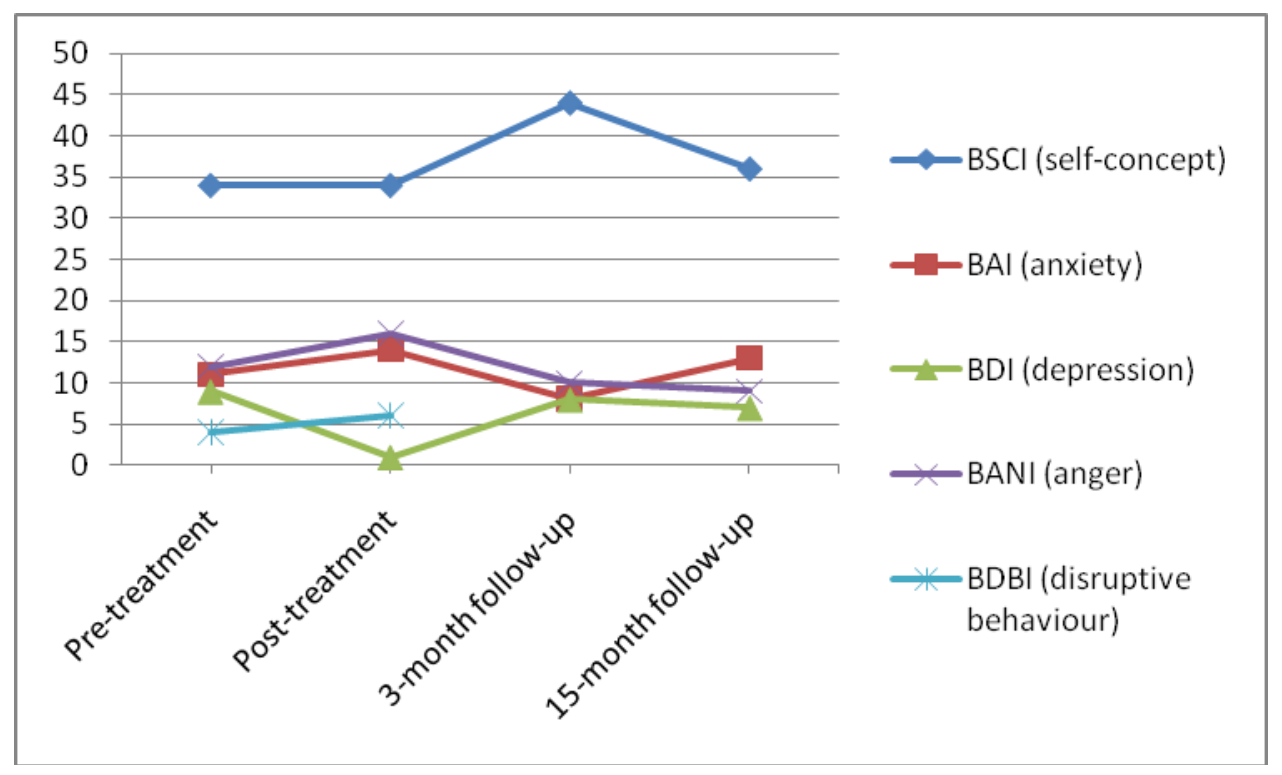

Figure 9. Erik’s Self-Ratings on the BYI 
A "Cool Kids" Cognitive-Behavioral Therapy Group for Youth with Anxiety Disorders:

Part 1, The Case of Erik

I. Lundkvist-Houndoumadi \& M. Thastum

Pragmatic Case Studies in Psychotherapy, http://pcsp.libraries.rutgers.edu

Volume 9, Module 2, Article 2, pp. 122-178, 06-26-13 [copyright by authors]

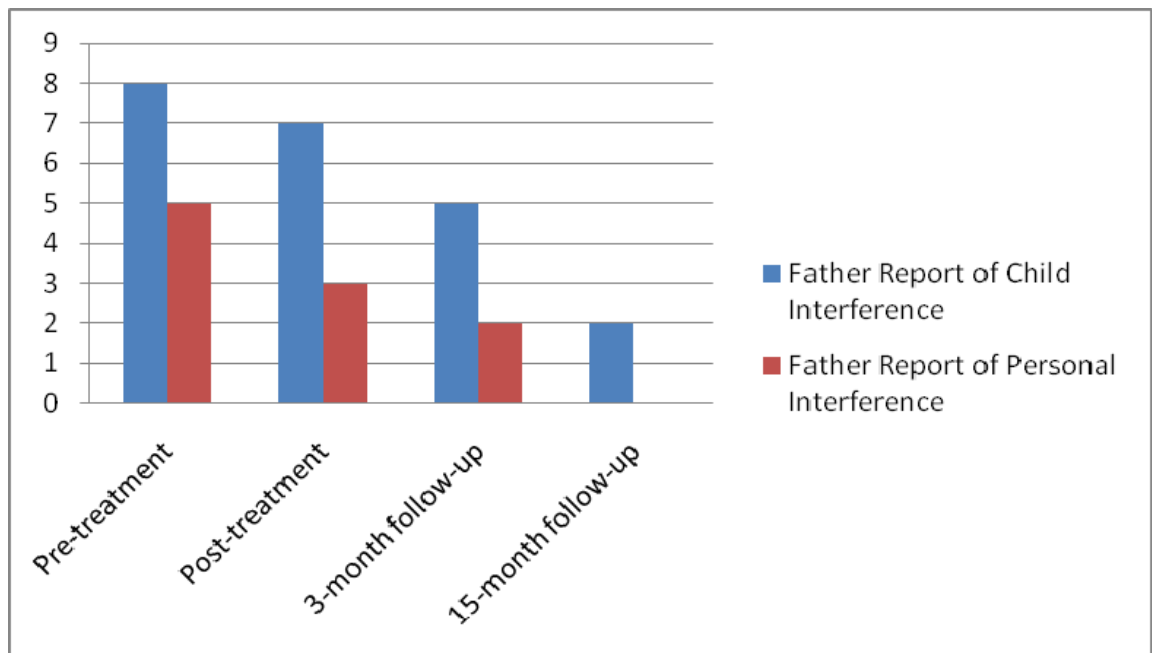

Father's ratings

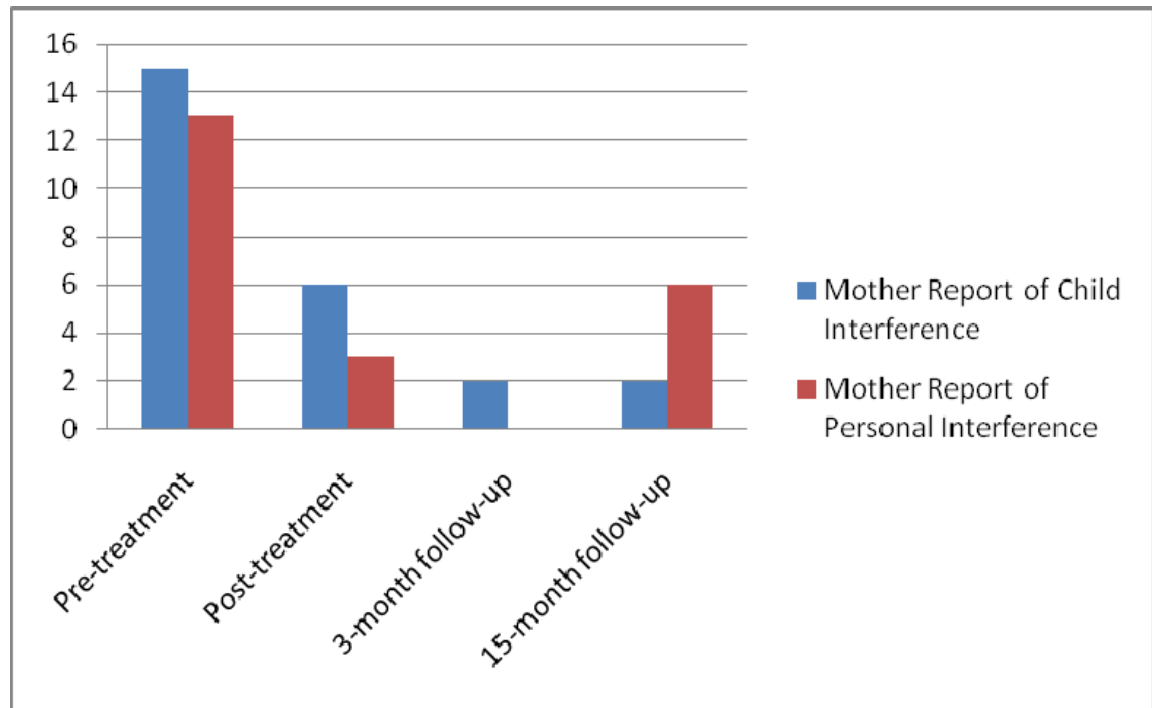

Mother's ratings

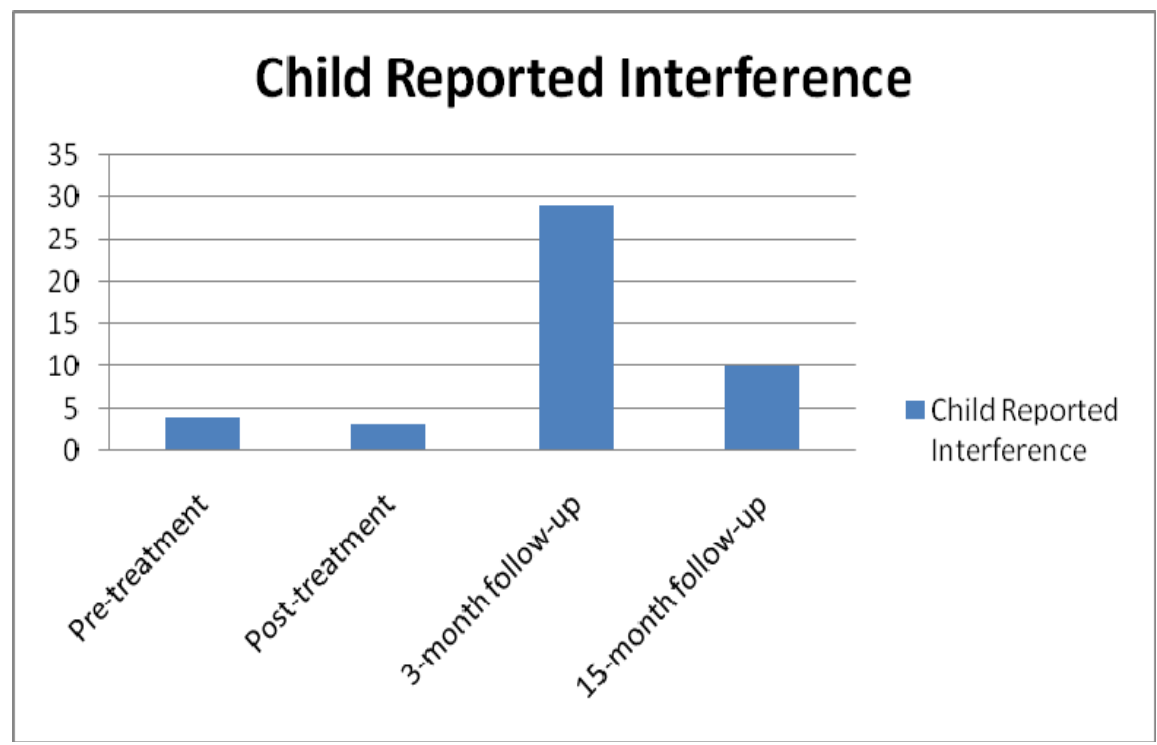

Figures 10-12. Ratings on the CALIS at Different Points in Time

Erik's ratings
Figures 10-12. Ratings on the CALIS at Different Points in Time 